\title{
Antioxidant and Anti-inflammatory Mechanisms of Neuroprotection by Ursolic Acid: Addressing Brain Injury, Cerebral Ischemia, Cognition Deficit, Anxiety, and Depression
}

\author{
Solomon Habtemariam \\ Pharmacognosy Research Laboratories \& Herbal Analysis Services, University of Greenwich, Central Avenue, Chatham-Maritime, \\ Kent ME4 4TB, UK \\ Correspondence should be addressed to Solomon Habtemariam; s.habtemariam@herbalanalysis.co.uk \\ Received 27 February 2019; Revised 27 April 2019; Accepted 8 May 2019; Published 16 May 2019 \\ Academic Editor: José P. Andrade \\ Copyright (c) 2019 Solomon Habtemariam. This is an open access article distributed under the Creative Commons Attribution \\ License, which permits unrestricted use, distribution, and reproduction in any medium, provided the original work is \\ properly cited. \\ Ursolic acid (UA) is a pentacyclic triterpene which is found in common herbs and medicinal plants that are reputed for a variety of \\ pharmacological effects. Both as an active principle of these plants and as a nutraceutical ingredient, the pharmacology of UA in the \\ CNS and other organs and systems has been extensively reported in recent years. In this communication, the antioxidant and anti- \\ inflammatory axis of UA's pharmacology is appraised for its therapeutic potential in some common CNS disorders. Classic \\ examples include the traumatic brain injury (TBI), cerebral ischemia, cognition deficit, anxiety, and depression. The \\ pharmacological efficacy for UA is demonstrated through the therapeutic principle of one drug $\rightarrow$ multitargets $\rightarrow$ one/many \\ disease(s). Both specific enzymes and receptor targets along with diverse pharmacological effects associated with oxidative stress \\ and inflammatory signalling are scrutinised.
}

\section{Introduction}

Ursolic acid (UA) is a common name for the plant triterpenoid compound, 3 3 -hydroxy-12-ursen-28-ic acid. The general biosynthetic routes of terpenoids are depicted in Figure 1 and start from the basic metabolic precursor, acetyl coenzyme A. Since mevalonic acid is an intermediate for terpenoid synthesis, including cholesterols and steroids in animals, this biosynthesis route is also called the mevalonate pathway. The basic building blocks of terpenoids are the five carbon isoprene units that exist in nature in highly reactive isopentenyl pyrophosphate (IPP or isopentenyl diphosphate) and its isomer, dimethylallyl pyrophosphate (DMAPP, dimethylallyl diphosphate). The sequential addition of two, three, and four isoprene units leads to the basic skeletons of the monoterpenoid, sesquiterpenoid, and diterpenoid precursors, respectively, as geranyl, farnesyl, and geranylgeranyl pyrophosphates. All triterpenes are products of two farnesyl pyrophosphate units joined together in head-to-head fashion and trace their acyclic precursor as squalene (Figure 1).

One of the nature's wonder in structural diversity of plant secondary metabolites is reflected through the identification of well over 20,000 triterpenes from just a single squalene precursor. In the first instance, glycosylation to give the diverse saponins and related complex structures is the common route of structural diversity. Beyond oxidations to give the hydroxyl and common carboxylic acid derivatives, cyclisation patterns of terpenoids are the major source of structural diversity. For the triterpenes, the pentacyclic skeletons are among the most common and include the oleanane and ursane groups, among others (e.g., lupanes, gammaceranes, and hopanes). The difference between oleanane and ursane is based on the migration of one methyl group (C-30) in the latter compound from C-20 to C-19 position. The common derivatives of these two compounds are based on C-3 hydroxylation, C-28 carboxylation, and a double bond at C12 position to form UA and oleanolic acids while further 

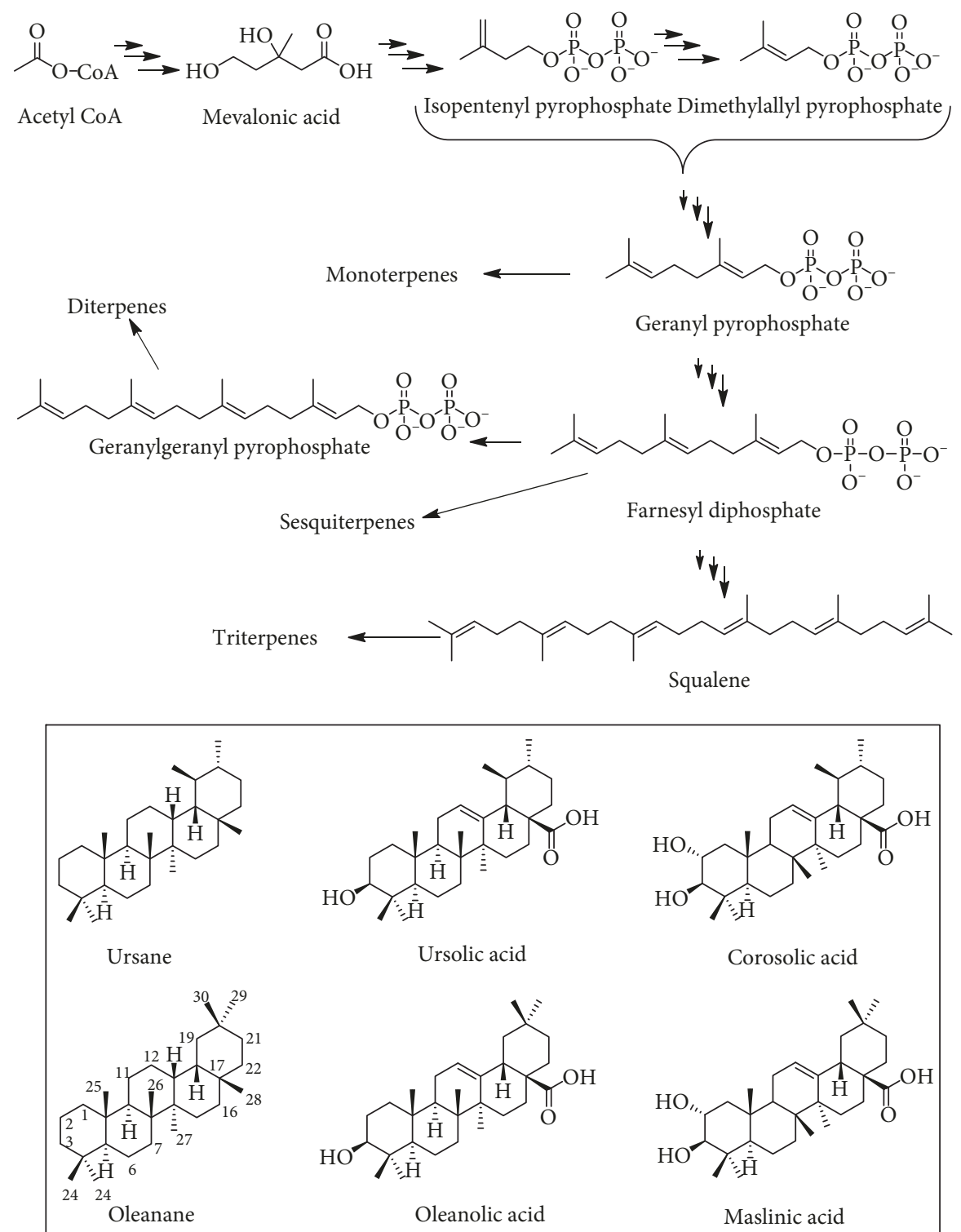

FIGURE 1: Common biosynthesis pathway of triterpenes including ursolic, oleanolic, corosolic, and maslinic acids.

hydroxylation at C-2 position gives corosolic acid and maslinic acid (Figure 1). These two groups of pentacyclic structures both in their aglycone and glyosidic forms are known for a range of biological activities.

Despite its common occurrence in nature including in herbs such as basil, rosemary, and sage or common fruits including apple and pears, UA has diverse pharmacological effects. Some of these effects are reviewed in recent years and include brief overviews of pharmacology related to anticancer [1,2], antiobesity [3,4], neurodegenerative, and other diseases [5]. While the anti-inflammatory effect of UA and other triterpenes is widely known [6], it does not possess direct reactive oxygen species (ROS) scavenging effect. This is understandable considering its structure (Figure 1) that lacks the phenolic structural moiety which is often linked to radical scavenging and metal ion chelation pharmacology. A plethora of studies, however, suggest that UA has antioxidant effects in vivo through upregulation of antioxidant defenses. Hence, through the combined antioxidant and anti-inflammatory mechanisms, the compound is endowed with a unique potential to ameliorate a range of neuronal diseases. This review addresses the role of UA in brain injury, cerebral ischemia, cognition deficit, anxiety, and depression through the two common (oxidative and inflammatory) pathological pathways along with specific actions on receptors and enzymes.

\section{Traumatic Brain Injury and Spinal Cord Injury}

Traumatic brain injury (TBI) refers to pathological events related to alteration of the brain function as a result of direct damage by external force such as a blunt to the head. The resulting widespread axonal injuries and lesions in various regions of the CNS could lead to symptomatic abnormalities in cognitive and motor functions, behavioral and emotional 
domains. The most common and long-lasting abnormality associated with TBI however remains to be memory-related cognitive impairment [7]. Following the primary neuronal tissue damage in TBI, a range of metabolic dysregulation including ischemia, excitotoxicity, calcium, and mitochondrial dysregulations ultimately leads to the inflammationmediated secondary neuronal damage. Hence, it is reasonable to include anti-inflammatory interventions in the neuroprotective approach of TBI therapy either by pharmacological agents to suppress the overactivated microglia (or astrocytes) [8-10] or by other means such as cell replacement therapies [11] which are yet to be proven to be effective under clinical conditions. The neuroinflammation approach of TBI management should also be seen as targeting the chronic inflammatory events while leaving the normal microglial function intact.

The significance of TBI and, to a lesser extent, spinal cord injury (SCI) has been reviewed in recent years by various authorities. According to the GBD collaborator group study [12], the global incidence of new cases for TBI in 2016 was 27.08 million and SCI was 0.93 million, while their global prevalence was 55.50 million and 27.04 million, respectively. TBI and SCI are classic examples of CNS diseases where new neuronal growth or neurogenesis offers a real potential to regain normal function. Although the significance of neurogenesis in adulthood is well established in experimental animals, there is no consensus for its role in humans. Some evidences show that neurogenesis in the hippocampus of adult humans persists throughout old age [13-15]. On the other hand, the level of neurogenesis has been shown to drastically drop below the detection level even in children [16]. Considering neurogenesis event, particularly at the subgranular zone of the dentate gyrus of the hippocampus, is associated with learning and memory, its role in humans is in need of more research. However, there is still a great deal of enthusiasm in the search of novel compounds that enhance neurogenesis in adulthood as demonstrated for numerous natural products such as curcumin, resveratrol, (-)-epigallocatechin-3-gallate (EGCG), and berberine that increase the production of neurotrophins such as the brain-derived neurotrophic factor (BDNF) or its receptor agonists [17]. Since these natural products are known for their potent antioxidant properties, the dual antioxidant-anti-inflammatory axis along with their multifunctional effects could make them considered as potential therapies for TBI and related pathologies.

The activation and subsequent translocation of the nuclear factor-erythroid 2-related factor 2 (Nrf2) are induced by a variety of stimuli including oxidative stress leading to the transcriptional activation of antioxidant genes such as heme oxygenase-1 (HO-1), GST, NADPH quinone oxidoreductase-1 (NQO-1), and SOD. On the basis that UA exert antioxidative and anti-inflammatory effects on cerebral ischemia by activating the Nrf2 pathway, Ding et al. [18] evaluated the effect of UA on the TBI model in mice (Table 1). In their $24 \mathrm{~h}$ assay after TBI induction, administration of UA $(50-150 \mathrm{mg} / \mathrm{kg})$ has been shown to reduce brain oedema and neurological insufficiencies. The increased nuclear translocation of Nrf2 protein coupled with the increased expression of NQO1 and HO-1 suggests the role of the antioxidant and/or inflammatory pathway in the neuroprotective effects induced by UA (see also the following section). Moreover, UA was shown to augment the expression level of protein kinase B (Akt), suggesting the activation of the Nrf2 signalling pathway as a mechanism of brain protection under TBI.

Zhang et al. [19, 20] employed a subarachnoid haemorrhage brain injury model in rats to study the potential effect of UA administration ( 25 or $50 \mathrm{mg} / \mathrm{kg}$ ) over a $48 \mathrm{~h}$ observation period. From the inflammatory end-point measurement that they recorded, a significant reduction of the treatment group included intercellular adhesion molecule-1 (ICAM$1)$, toll-like receptor 4 (TLR 4$)$, nuclear factor $-\kappa \mathrm{B}(\mathrm{NF}-\kappa \mathrm{B})$ P65, interleukin- $1 \beta$ (IL- $1 \beta$ ), tumor necrosis factor- $\alpha$ (TNF$\alpha$ ), interleukin-6 (IL-6), inducible nitric oxide synthase (iNOS), and matrix metalloproteinase- (MMP-) 9. These anti-inflammatory effects coupled with a reduction in the apoptosis score suggest the neuroprotective effect of the compound [19]. On the antioxidant line of evidence, the attenuation of early brain injury such as brain oedema, blood-brain barrier disruption, neural cell apoptosis, and neurological deficient by the compound was shown to be coupled with antioxidant levels in the rat cerebral cortex [19]. This include suppression of the malondialdehyde (MDA) levels, increased ratio of reduced (GSH) to oxidized (GSSG) glutathione, recovery of the suppressed superoxide dismutase (SOD), and catalase (CAT) activities, while the markers of apoptosis, caspase- 3 and caspase- 9 (mRNA and protein levels), were suppressed.

An interesting insight into the neuroregeneration and regrowth potential of UA has been investigated by Sahu et al. [21] using the mouse model of spinal cord injury (Table 1). They have shown that UA (100 or $200 \mathrm{mg} / \mathrm{kg}$ ) administered $1 \mathrm{~h}$ after and then once daily for 6 weeks could promote the recovery of motor functions and axonal regrowth while decreasing astrogliosis. Moreover, UA suppressed the level of proinflammatory cytokines such as IL-6 and TNF- $\alpha$ in the injured spinal cord while activating the mitogen-activated protein kinase (MAPK) and phosphoinositide 3-kinase (PI3K)/Akt/mammalian target of rapamycin (mTOR) pathways in the injured spinal cord.

\section{Cerebral Ischemia}

Perhaps the best pathological disease associated with cerebral ischemia is the cerebrovascular disease (stroke) which results from either disruption of blood supply (ischemia) or haemorrhage. Li et al. [22] studied the neuroprotective effect of UA through the transient middle cerebral artery occlusion (MCAO) model of focal cerebral ischemia in mice (Table 1 ). In the $24 \mathrm{~h}$ assay after stroke, administration of $130 \mathrm{mg} / \mathrm{kg}$ (i.p.) of UA led to a significant reduction in infarct size coupled with low level of lipid peroxidation (LPO) marker, MDA. In the latter case, the antioxidant effect was coupled with the induction of the nuclear expression of Nrf2 and HO-1 both at the protein and mRNA levels. On the other hand, the cytoplasmic protein level of Nrf2 in ischemic brain at $24 \mathrm{~h}$ after MCAO was shown to 


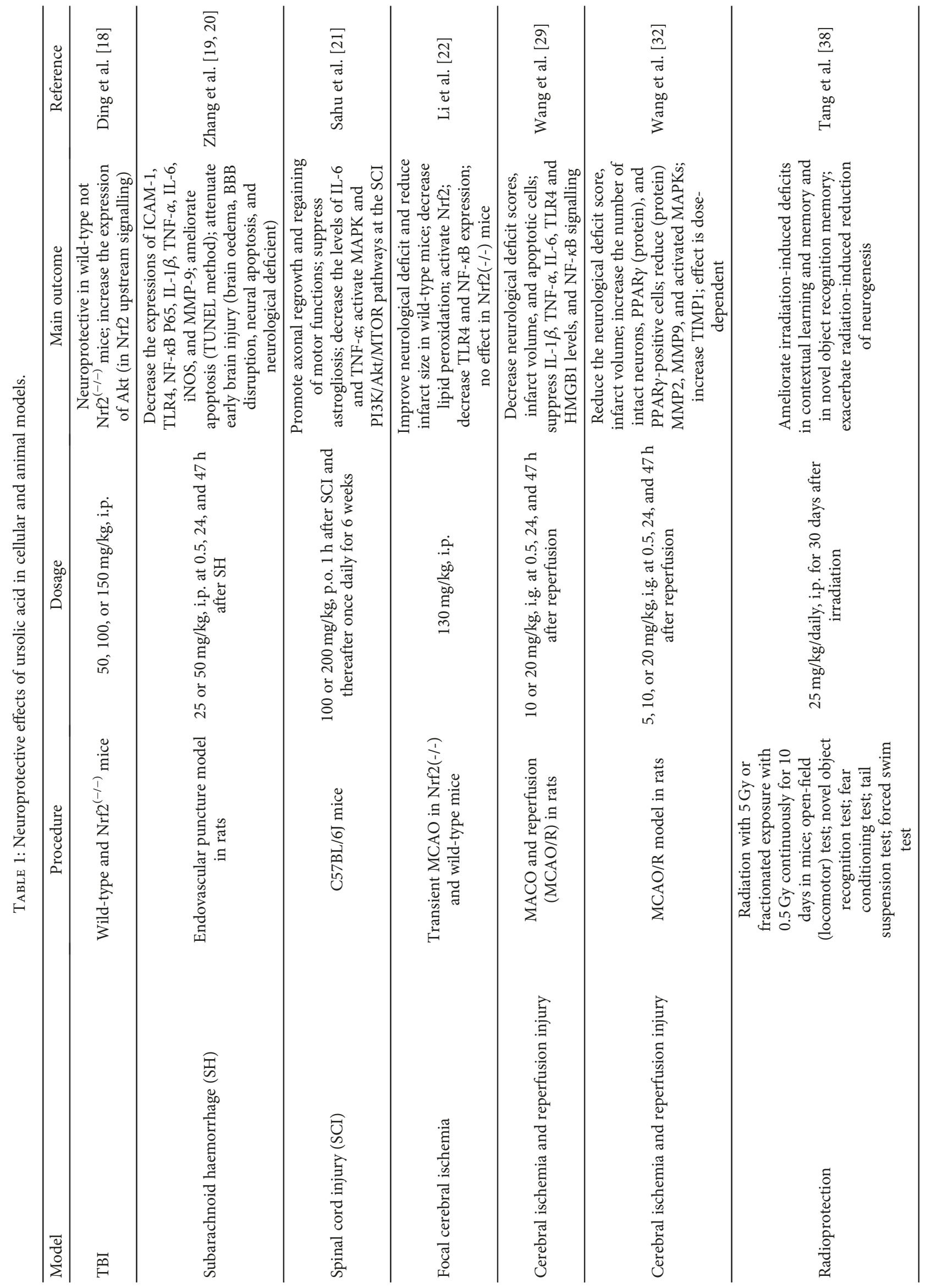




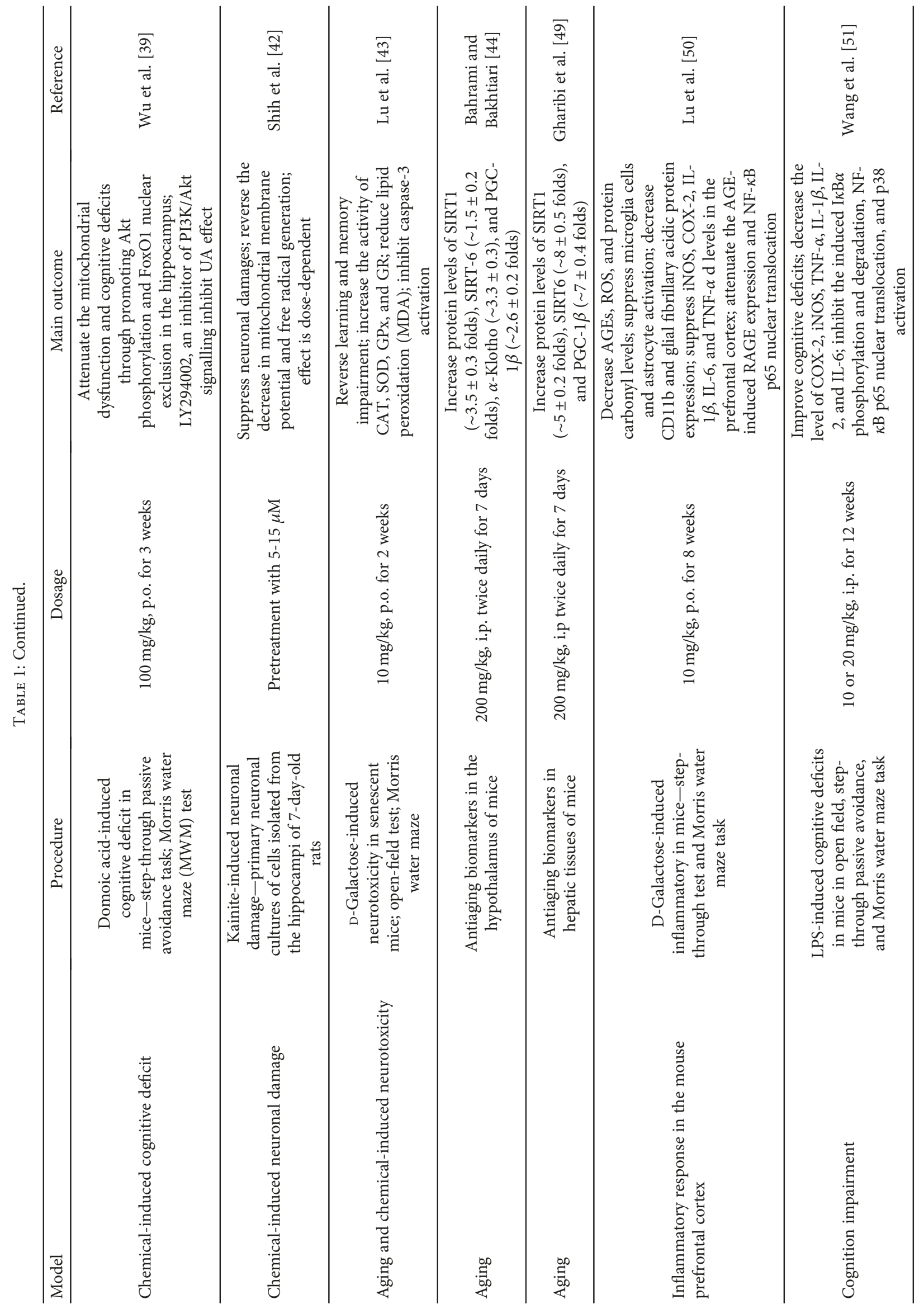




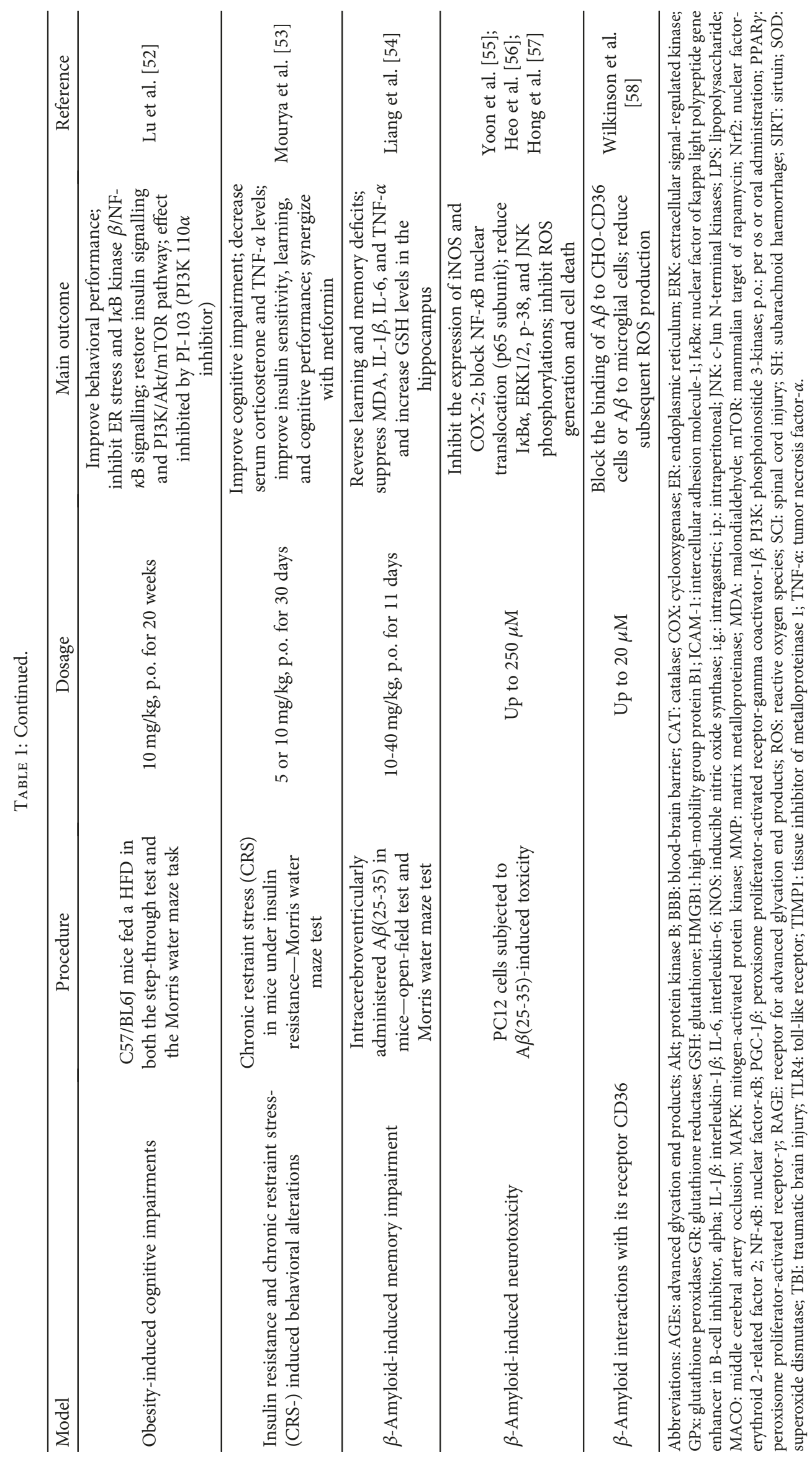


be suppressed by UA. As an anti-inflammatory agent, treatment with UA also suppressed the level of expression (both at mRNA and protein levels) of TLR 4 and NF- $\kappa$ B after stroke in mice. Since $\mathrm{Nrf2}^{-1-}$ mice were more susceptible to neuronal damage (infarct size and oxidative and inflammatory scores) in the MCAO model and UA does not extend its protective effect in this mouse group, the Nrf2 signalling pathway is at the forefront of the potential mechanism of action for UA. Hence, the effect of UA is consistent to the well-known effect of the Nrf2-antioxidant response element signalling pathway in oxidative stress $[23,24]$ and neuroprotection under a variety of CNS disorders including aging [25-28].

In another MCAO model in rats (see Table 1), the beneficial effect of UA in cerebral ischemia and reperfusioninduced brain injury in rats was studied by Wang et al. [29]. When UA was administered (10 or $20 \mathrm{mg} / \mathrm{kg}$, i.g.) at $0.5,24$, and $47 \mathrm{~h}$ after reperfusion, decreased neurological deficit scores such as infarct volume and apoptotic cells were observed. The anti-inflammatory mechanism was evident from the reduced level of proinflammatory cytokine concentrations (IL- $1 \beta$, TNF- $\alpha$, and IL-6), TLR4, and inactivated NF- $\kappa \mathrm{B}$, while the high-mobility group box 1 (HMGB1) was also inhibited. In the latter case, HMGB1 is a prominent member of damage-associated molecular patterns (DAMPs) which is released during brain damage, and its binding activity with the DNA is known to induce inflammatory signalling. A number of studies have also shown that HMGB1 can be passively released from necrotic cells or actively secreted in response to inflammatory signals [30]. Working with synergism with the inflammatory pathway, the HMGB1 receptors include the receptors for advanced glycation end products (RAGEs) and toll-like receptor 2 (TLR2) and TLR4. The addition of HMGB-1 in cultured glia and endothelial cells has further been shown to increase the level of TNF- $\alpha$ and ICAM- 1 , respectively, while in the MCAO model, the release of HMGB-1 from neurons at the earliest onset of brain ischemia was demonstrated [31]. Wang et al. [32] also used a MACO model with similar protocol of cerebral ischemia and reperfusion injury and UA administration $(5-20 \mathrm{mg} / \mathrm{kg}$, i.g.). They have shown that the improvement in neurological deficit scores such as infarct volume and the number of intact neurons by UA was associated with dose-dependent reduction in the protein levels of MMP2, MMP9, and activated MAPKs, while the level of tissue inhibitor of metalloproteinases 1 (TIMP1) was increased. Furthermore, the protective effect was not only shown to be associated with the increased level of the peroxisome proliferator-activated receptor- $\gamma$ (PPAR- $\gamma$ ) protein level and the percentage of PPAR- $\gamma$-positive cells by UA treatment but also the neuroprotective effect of UA could be ameliorated by a PPAR- $\gamma$ antagonist (bisphenol A diglycidyl ether). Hence, the anti-inflammatory effect of UA as a mechanism includes suppression of the metalloprotease/antimetalloprotease imbalance through action as PPAR- $\gamma$ agonist.

\section{Cognition Deficit}

According to the Alzheimer's Disease International [33], the global figure for dementia in 2015 was 46.8 million people and was estimated to reach close to 50 million people in 2017 with a further projection of doubling every 20 years to reach 75 million by 2030 or 131.5 million in 2050 . There is now also over 9.9 million new cases of dementia each year worldwide. The same source put the global cost of dementia as US $\$ 818$ billion in 2015 or US $\$$ trillion in 2018 . The most common form of dementia is Alzheimer's disease (AD) which is an age-related disease characterised by amyloid- $\beta$ $(\mathrm{A} \beta)$ plaque deposition at the interneuronal space and neurofibrillary tangles primarily by the microtubule-associated protein, tau, phosphorylation. The therapeutic approaches of dementia are one of the most challenging and what we should still consider at its infancy stage despite the great level of understanding in dementia pathology. Numerous review articles are available in this field (e.g., [34-37]), and herein, the emphasis is to appraise experimental evidences showing pharmacological efficacy for UA. Some of the key findings are summarized in Table 1.

4.1. Radio-Induced and Chemically Induced Memory Deficit. The radioprotective effect of UA in mice was evaluated by Tang et al. [38] using the experimental model based on administering $25 \mathrm{mg} / \mathrm{kg} /$ daily $1 \mathrm{~h}$ after acute $(5 \mathrm{~Gy})$ or continuous $(0.5 \mathrm{~Gy})$ irradiations for 30 days. They have reported that UA could improve acute irradiation-induced deficits in contextual learning and memory and in novel object recognition memory. The treatment however exacerbated the radiation-induced reduction of neurogenesis in the subgranular zone. Administration of domoic acid in mice can induce cognitive deficits associated with mitochondrial dysfunction which was shown to be ameliorated by UA via modulation of the PI3K/Akt and forkhead box protein O1 (FoxO1) signalling pathways [39]. In this model, FoxO1 activation appear to mediate the mitochondrial dysfunction and memory deficits as FoxO1 knockdown reversed the pathological score induced by domoic acid. Furthermore, the oxidative stress-induced c-Jun $\mathrm{N}$-terminal kinase (JNK) activation and decreased Akt phosphorylation in the hippocampus of domoic acid-treated mice could all be reversed by UA along with the pathological score, promotion of Akt phosphorylation, and FoxO1 nuclear exclusion. As a structural analogue of kainic acid, domoic acid is a natural neurotoxin that induce excitotoxicity in neuronal cells. It is also known to be a toxic agent in the occasional poisoning of people who consume muscles contaminated with the marine planktonic diatom source of domoic acid. The neurological squeal of domoic acid in humans and neurological deficits in experimental animals have already been outlined [40, 41]. In this context, UA has also been shown to protect hippocampal neurons against the kainic acid-induced excitotoxicity [42]. In primary neuronal cultures of cells isolated from the hippocampi of 7-day-old rats, the kainite-induced cell damage and decrease in the mitochondrial membrane potential could be reversed by UA $(5-15 \mu \mathrm{M})$. In senescent mice subjected to D-galactose-induced neurotoxicity, UA ( $10 \mathrm{mg} / \mathrm{kg}$, p.o. for 2 weeks) has been shown to improve memory (Morris water maze model) along with increased antioxidant enzymes SOD, CAT, glutathione peroxidase $(\mathrm{GPx})$, and glutathione reductase (GR) and reduction in 
the level of LPO (MDA) [43]. On the other hand, the activation of caspase- 3 in neuronal tissues was suppressed while the level of neural growth-associated protein GAP43 was increased by UA. This data imply that the key regulatory protein for axonal elongation, synaptic plasticity, and nerve sprouting in adult animals that diminishes under experimental dementia could be restored by UA, while apoptosis is suppressed. Related to the age-associated dementia is also the potential effect of UA on the level of antiaging proteins in the brain. Bahrami and Bakhtiari [44] have shown that UA administration $(200 \mathrm{mg} / \mathrm{kg}$, i.p for 7 days) could increase sirtuin 1 (SIRT1), SIRT-6, $\alpha$-Klotho, and peroxisome-proliferator-activated-receptor $\gamma$ coactivator 1 beta (PGC-1 $\beta$ ) protein levels in the isolated hypothalamus (Table 1). While SIRT and PGC- $1 \beta$ are known regulators of energy balance such as mitochondrial function, $\alpha$-Klotho is regarded as a hormone that potentially suppress aging as its deficiency is shown to accelerate the degeneration of multiple agesensitive traits (e.g., [45-48]). The hepatoprotective effect of UA was similarly linked with the generation of the abovementioned antiaging biomarkers in mice as follows: SIRT1, SIRT6, PGC-1 $\beta$, and Klotho protein expression [49].

The D-galactose-induced neurodegenerative changes were also shown to display the therapeutic potential of UA through antioxidant and anti-inflammatory mechanisms. In addition to improved behavioral performance in mice in the step-through test and Morris water maze task, treatment with UA was shown to decrease advanced glycation end products (AGEs), receptors for AGEs, ROS, and protein carbonyl levels in the prefrontal cortex [50]. As antiinflammatory compound, UA also suppressed the number of activated microglia cells and astrocytes along with the decreased expression level of adhesion molecule CD11b and glial fibrillary acidic protein, while the expressions of iNOS, cyclooxygenase- 2 (COX- 2 ), NF- $\kappa$ B, IL- $1 \beta$, IL- 6 , and TNF- $\alpha$ levels were all shown to be suppressed [50].

The lipopolysaccharide- (LPS-) induced cognitive deficits are one of the best experimental model to show the link between the therapeutic potential of experimental agents in memory function via anti-inflammatory mechanism. In mice treated with LPS, UA (10 or $20 \mathrm{mg}$, i.p. along with LPS for 8 weeks) was shown to improve cognitive deficits in open field, step-through passive avoidance, and Morris water maze tasks, while the level of proinflammatory markers such as COX-2, iNOS, TNF- $\alpha$, IL- $1 \beta$, IL-2, and IL-6 in the LPS-treated mouse brain was suppressed [51]. Moreover, UA was shown to suppress the LPS-induced $\mathrm{I} \kappa \mathrm{B} \alpha$ phosphorylation and degradation, NF- $\kappa \mathrm{B}$ p 65 nuclear translocation, and p38 activation in the mouse brain although it did not alter the activation of TLR4, MyD88, ERK, JNK, and Akt.

4.2. Diet and/or Diabetes-Induced Memory Deficit. As a model of obesity-induced cognitive impairments, Lu et al. [52] employed a high-fat diet- (HFD-) fed mice to show the promise of UA ( $10 \mathrm{mg} / \mathrm{kg}$, p.o. for 20 weeks) as a neuroprotective agent. The improvement of the cognition score in both the step-through test and the Morris water maze task was shown to be associated with inhibition of endoplasmic reticulum (ER) stress and $\mathrm{I} \kappa \mathrm{B}$ kinase $\beta /$ nuclear factor- $\kappa \mathrm{B}$ mediated inflammatory signalling and the restoration of the insulin signalling and PI3K/Akt/mammalian target of rapamycin (mTOR) pathway. Considering the abolition of the observed protective effect by a specific PI3K 110a inhibitor, the classical example of improvement of the insulin signalling pathway relevant to diabetes and/or obesity-mediated insulin resistance and memory deficit was demonstrated for UA. In fact, one of the best-characterised pharmacological effects of UA is related to amelioration of insulin resistance and antidiabetic properties through a variety of mechanisms. In this regard, UA $(10 \mathrm{mg} / \mathrm{kg})$ by its own but even better in combination of metformin $(150 \mathrm{mg} / \mathrm{kg})$ has been shown, not only to enhance insulin sensitivity but also to improve cognitive impairment [53]. As one expects, this effect is associated with antioxidant and anti-inflammatory mechanisms.

4.3. Amyloid-Beta- (A $\beta$-) Related Pharmacology. Perhaps one of the most researched and promising proof of concept and also the basis for the spectacular failure rate in the history of drug development is related to amyloid- $\beta(\mathrm{A} \beta)$ as a target for AD. The recent disappointment in phase III clinical trials has included major player in the pharmaceutical industry including the Merck, Pfizer, J\&J, Eli Lilly, and Roche which all have $\mathrm{A} \beta$ as a common target. Numerous explanations may be given for these failures including the patients' heterogeneity in disease pathology, the rather long duration of the disease pathology, $A \beta$ may not even be correlating with disease pathology in some cases, or it may even be too late to target it by the time the disease has progressed or the symptom is displayed by patients. The source of dementia, for example, could be of cortical origin which itself could be of $\mathrm{AD}$ or frontotemporal dementia; subcortical dementia of Parkinson's disease (PD), Huntington's disease, or Lewy body dementia origin; vascular; or mixed dementia. These different forms might have some common symptoms but differ in their pathological features and hence might not be overcome by common therapeutic approach. As the principal protein component of the senile plaques and overwhelming experimental evidence including animal studies linking $\mathrm{A} \beta$ to neurotoxicity and Alzheimer's disease, however, the amyloid hypothesis as a proof of concept is still as attractive as it has ever been. Inhibition of $A \beta$ formation, removal or clearance, or neuroprotection approach is therefore worthwhile to evaluate the therapeutic potential of natural products for $\mathrm{AD}$.

When learning and memory deficits in mice were induced by injection of aggregated $\mathrm{A} \beta 25-35$ into lateral ventricles of mice, UA $(10,20$, or $40 \mathrm{mg} / \mathrm{kg}$, p.o. for 11 days) could reverse the behavioral hallmark of $\mathrm{AD}$ (Morris water maze test) along with inhibition of lipid peroxidation (MDA level) and enhancement of the antioxidant (glutathione (GSH)) level in the hippocampus [54]. The inflammatory markers as shown for the reduced level of IL- $1 \beta$, IL- 6 , and TNF- $\alpha$ levels were also ameliorated in the hippocampus. In vitro, ursolic acid isolated from Corni fructus was also shown to ameliorate the $\beta$-amyloid(25-35)-induced toxicity in PC12 cells via modulation of the NF- $\kappa \mathrm{B}$ signalling pathway [55]. Hence, the A $\beta$-induced expression of iNOS and COX-2 was inhibited through blockade of nuclear 
translocation of the p65 subunit of NF- $\kappa \mathrm{B}$ and phosphorylation of $\mathrm{I} \kappa \mathrm{B} \alpha$, along with reduced ERK1/2, p-38, and JNK phosphorylation. In PC12 neuronal cells, the increase in free radical production, LPO, and apoptosis induced by $\mathrm{A} \beta$ could also be reversed by UA isolated from Origanum majorana L. [56, 57].

In Chinese hamster ovary cells stably expressing the human CD36, a drug screening programme identified UA as an inhibitor of $A \beta$ protein interactions with its receptor CD36: the interaction of $\mathrm{A} \beta$ to $\mathrm{CD} 36$ could be inhibited by ursolic acid up to a maximal inhibition level of $64 \%$ at $20 \mu \mathrm{M}$ [58]. Since CD36 is one of the several receptors for $\mathrm{A} \beta$ (e.g., $[59,60]$ ), inhibition of $\mathrm{A} \beta$ binding by UA could contribute to the memory-enhancing effect of the compound in vivo.

4.4. Acetylcholinesterase Inhibition. Chung et al. [61] identified Origanum majorana as a promising acetylcholinesterase (AChE) inhibitor from their screening studies on 139 plant species. A further attempt to identify the active principles led to the identification of UA as an active principle which displayed the in vitro $\mathrm{IC}_{50}$ value of $7.5 \mathrm{nM}$ in comparison to $1 \mathrm{nM}$ for tacrine. With the hope of increasing potency, UAderived hydroxyl-propinyl derivatives have been synthesised and 2-methyl-3-oxo-methyl-ursoloate, for example, as an AChE and butyrylcholinesterase inhibitor in the lower micromolar range has been reported [62]. Since AChE inhibition is by far the best characterised targets for the handful of clinically validated therapeutic agents of $\mathrm{AD}$, further research in this area to identify a more potent UA analogues is well justified.

\section{Depression and Anxiety}

The role of inflammation in anxiety and mood disorders has been well established. A review of clinical and translational data has consistently shown that inflammation could induce the effect on the basal ganglia and cortical reward and motor circuits leading to a reduced level of motivation and motor activity, while the effects of proinflammatory cytokines on monoamines and glutamate could affect the anxiety-related brain regions including amygdala, insula, and anterior cingulate cortex [63]. This relationship is even more prevalent under depressive conditions as inflammatory pathways are activated in depressed patients [64] or in experimental animals $[65,66]$. The relationship between inflammatory diseases and depression has also been extensively reviewed and includes cytokine-mediated depression development in patients with connective tissues [67], neuroinflammation in cognitive impairment under psychiatric conditions (e.g., major depressive disorder, bipolar disorder, schizophrenia, and posttraumatic stress disorder) [68], central and peripheral inflammation as the link between depressive disorders and metabolic syndrome [69], and anti-inflammatory intervention as means of managing depressive disorders [70]. Oxidative stress is similarly a major component of anxiety pathology although whether it is the cause or a pathological consequence of the disease is still in need of further research. Insight into the evidences for such correlation from experimental and clinical studies has been reviewed [71], and similarly, the role of antioxidant compounds in depressive-like diseases has been appraised [72]. In this context, the effect of UA as anti-inflammatory and antioxidant agent along with other specific effects in depression and anxiety pharmacology is outlined in the following text (see also Table 2).

The anticonvulsant properties of UA have also been shown in various animal models of epilepsy and seizures. The seizure models in mice employed by Nieoczym et al. [73] included the $6 \mathrm{~Hz}$ induced psychomotor seizure threshold test, the maximal electroshock threshold (MEST) test, and the timed intravenous pentylenetetrazol (i.v. PTZ) infusion test. They have shown that UA (50 and $100 \mathrm{mg} / \mathrm{kg}$, i.p.) could increase the seizure thresholds in the $6 \mathrm{~Hz}$ and MEST tests without affecting the motor coordination and muscular strength in mice. As an active principle of Nepeta sibthorpii Bentham, Taviano et al. [74] have also shown that oral administration of UA $(2.3 \mathrm{mg} / \mathrm{kg})$ could induce depressant effect on the CNS by reducing spontaneous motor activity and the number and lethality of pentylenetetrazol- (PTZ-) induced seizures. On the other hand, inhibition of the acetic acid-induced abdominal constriction was also shown for the same dose, while a higher dose $(20 \mathrm{mg} / \mathrm{kg})$ increased the reaction time in the hot-plate test (effect reversed by naloxone-opioid receptors mediated) suggesting analgesic effect.

Considering the role of monoaminergic neurotransmitters (serotonin, norepinephrine, and dopamine) in the mood physiology and depressive-like pathologies, attempts have also been placed to characterise the involvement of various neurotransmitter pathways in UA's pharmacology. It is also worth noting that our current pharmacotherapy options for depression are largely based on enhancement of the monoamine transmission system by using selective neuronal reuptake inhibitors of key transmitters such as serotonin or noradrenaline or inhibition of monoamine transmitters degrading enzyme, monoamine oxidase (MAO). The antidepressant therapeutic approach also involve the N-methyl-Daspartate (NMDA) receptor antagonism with the classical example of ketamine as antidepressant agent. The opioid system has been shown to be involved in the antidepressant-like effect of agents such as folic acid [75] or in the antinociceptive mechanisms of various antidepressants [76].

The tail suspension test (TST) and forced swimming test (FST) are two classical animal models of antidepressant-like effect evaluations where UA showed potent activity. The study by Machado et al. [77], for example, reported a reduction in immobility time in the TST (0.01 and $0.1 \mathrm{mg} / \mathrm{kg}$, p.o.) and in the FST $(10 \mathrm{mg} / \mathrm{kg}$, p.o.) in a similar manor to the positive controls, fluoxetine $(10 \mathrm{mg} / \mathrm{kg}$, p.o.), imipramine $(1 \mathrm{mg} /$ $\mathrm{kg}$, p.o.), and bupropion (10 mg/kg, p.o.). Moreover, by using selective receptor antagonist in the TST, they have shown that UA could induce antidepressant-like effect via the dopaminergic system through dopamine $\mathrm{D}_{1}$ and $\mathrm{D}_{2}$ receptor activation [77]. In a similar study using TST, Colla et al. [78, 79] demonstrated that the serotonergic and noradrenergic systems (but not the glutamatergic or opioid systems) are also involved in the antidepressant-like effect of UA. This is 


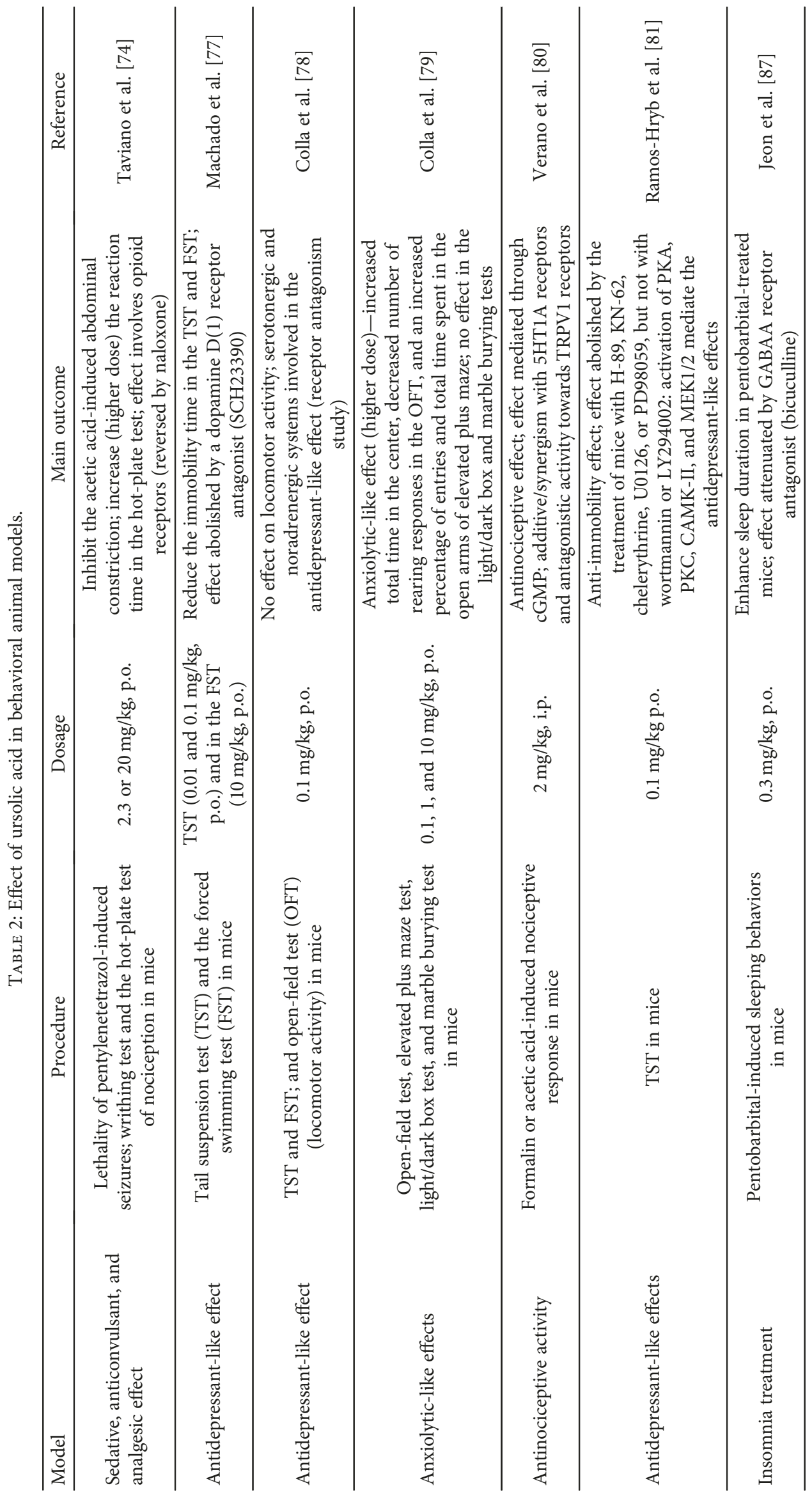


despite the fact that UA is known to induce antinociceptive effect including through modulation of TRPV1 receptors (antagonism), cGMP generation, and a serotonergic $\left(5 \mathrm{HT}_{1 \mathrm{~A}}\right.$ receptor) synergism [80].

The antidepressant-like effects of UA in mice were also demonstrated at just a small dose as $0.1 \mathrm{mg} / \mathrm{kg}$ and even through an oral route [81]. Through the TST, the antiimmobility effect of UA was shown to be abolished by a protein kinase A (PKA) (H-89), $\mathrm{Ca}^{2+} /$ calmodulin-dependent protein kinase II (CAMK-II) (KN-62), protein kinase $\mathrm{C}$ (PKC) (chelerythrine), and mitogen-activated protein kinase kinase 1/2 (MEK1/2) (U0126 or PD98059) inhibitors but not PI3K (wortmannin or LY294002) inhibitors. Hence, this data is in agreement with the induction of antidepressant-like effects by drugs through the activation of kinases such as PKA [82], PKC [83], and CAMK-II [84]. Although it does not seem to be involved in the antidepressant-like effect of $\mathrm{UA}$, activation of MEK1/2 is also known to be associated with such mechanism [85].

As one of the active principles of Artemisia indica, UA has been shown to display anticonvulsant, antidepressant, and anxiolytic activities in mice. While UA was a positive modulator of $\alpha 1 \beta 2 \gamma 2 \mathrm{~L} \quad \gamma$-aminobutyric acid (GABA)-A receptor, the observed anxiolytic activity of the compound could be ameliorated by flumazenil suggesting that it acts through the benzodiazepine-binding site of GABA receptors [86]. UA isolated from $P$. vulgaris has also been shown to enhance the pentobarbital-induced sleeping time in mice: an effect which was abolished by GABA receptor antagonist, bicuculline. At fairly small doses $(0.03,0.1$, or $0.3 \mathrm{mg} / \mathrm{kg}$ ) administered prior to pentobarbital, the effect of UA was shown to be associated with activation of GABAA receptors by increasing GABA concentrations in brain tissues [87]. Such effect could have implications for a range of CNS disorders including insomnia. As a key enzyme target for anxiety, epilepsy, and other neurological disorders, the GABA transaminase (GABA-T) was shown to be inhibited by ursolic acid (UA) although the effect observed at the concentration of $100 \mu \mathrm{g} / \mathrm{mL}$ was rather weak [88].

In mice treated with UA $(0.1,1$, or $10 \mathrm{mg} / \mathrm{kg}$, p.o. $)$, anxiolytic-like effect has been reported for the highest dose with increased total time in the center, decreased number of rearing responses in the open-field test, and an increased percentage of entries and total time spent in the open arms of elevated plus maze. This effect was also reported to be similar with diazepam (2 mg/kg, p.o.) [79]. Finally, in silico studies have shown a nonselective antidepressant action with strong binding affinity towards MAO-A protein [89] which might have some implication in cellular/animal models. UA also exhibited a significant inhibition of dopamine $\beta$-hydroxylase $(214 \mu \mathrm{mol} / \mathrm{L})$, weak inhibition of MAO-B $(780 \mu \mathrm{mol} / \mathrm{L})$, and no inhibition against MAO-A [90]. The high concentration used in this study to demonstrate pharmacological efficacy however seems to be therapeutically irrelevant. Overall, UA has both specific mechanisms of receptor and/or enzymemediated effects relevant to depression, anxiety, and related psychological disorders that may combine with known antioxidant and anti-inflammatory mechanisms of action in these diseases.

\section{Parkinson's Disease (PD)}

The pathological sequel of neuroinflammation and oxidative stress is best represented by Parkinson's disease (PD) which is characterised by the progressive loss of dopaminergic neurons in the substantia nigra region of the brain along with the formation of intracellular Lewy bodies (LBs) in viable neurons. The production of excessive amount of proinflammatory cytokines such as IL- $1 \beta$ and TNF- $\alpha$ along with ROS from overactivated microglial cells has long been known to orchestrate the PD pathology (e.g., [91-94]). Other classical inflammatory mediators include iNOS and COX-2 [95-97], p38 MAPK, and NF- $\kappa$ B pathway $[97,98]$. The interlinking $\mathrm{NF}-\kappa \mathrm{B}$ and p38 MAPK signalling pathways are also involved in both the oxidative stress and inflammatory components of neuronal damage in PD $[99,100]$. PD is therefore an ideal CNS pathology to demonstrate the therapeutic potential of UA that display anti-inflammatory and antioxidant activities in various animal models.

Animal models of PD are based on induction of oxidative stress and mitochondrial dysfunction by neurotoxins such as MPTP, rotenone, and paraquat. Upon entry into the CNS, MPTP is converted to $\mathrm{MPP}^{+}$via action by monoamine oxidase $\mathrm{B}(\mathrm{MAOB})$. The transport and subsequent accumulation of $\mathrm{MPP}^{+}$in dopaminergic neurons leading to amelioration of the mitochondrial electron transport system through interaction with complex I attribute to induction of PD in experimental animals. Hence, $\mathrm{MPP}^{+}$diminishes the mitochondrial power to generate ATP [101] and rather augment the formation of ROS such as superoxide anion. As a therapeutic intervention strategy, antioxidant mechanisms as well as inhibition of the MAOB activation which itself is dependent on the p38 MAPK pathway could be targeted. Some key references of the MPTP-induced PD model and ROS [102, 103] and MAPK [104] signalling pathways are available.

The MPTP-induced PD mouse model has been used to study the effect of UA $(5 \mathrm{mg} / \mathrm{kg}, 25 \mathrm{mg} / \mathrm{kg}$, and $50 \mathrm{mg} / \mathrm{kg}$, p.o. for 21 days). The treatment at the most effective dose of $25 \mathrm{mg} / \mathrm{kg}$ was shown to improve behavioral deficits, restored altered dopamine level, and protect dopaminergic neurons in the MPTP-intoxicated mouse [105]. It also ameliorated the MPTP-induced increase of MDA and nitric oxide (NO) levels which is in line with the antioxidant profile of UA in other CNS pathologies.

\section{General Antioxidant and Anti-inflammatory Effects of UA}

Direct ROS scavenging or their formation through metal chelation is a structural attribute endowed by phenolic compounds. Accordingly, compounds that possess the catechol functional group such as caffeic acids [106] and their derivatives including rosmarinic and salvianolic acids [107] or flavonoids such as rutin [108] and others [109] have been reported for their therapeutic potential in AD. Terpenoids could also share this function if they are to become aromatized and carry the phenolic structural moieties as shown for rosemary diterpenoids [110]. On the other hand, 


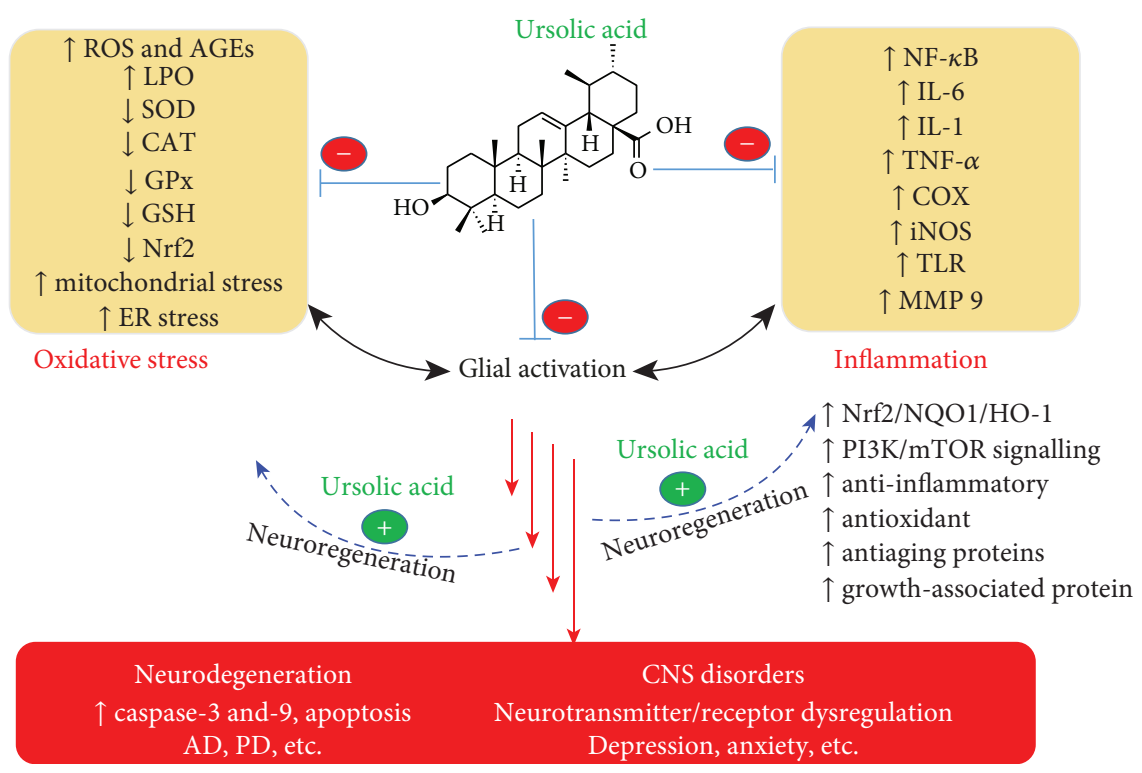

FIGURE 2: Anti-inflammatory and antioxidant mechanisms of neuroprotection and neuronal function by ursolic acid. Glial cells play a pivotal role in oxidative stress and neuroinflammation that are prevalent in various neurodegenerative disease, traumatic brain/spinal cord injuries, and psychological disorders. By suppressing the generation of ROS, AGEs, and lipid peroxidation (LPO) products as well as increasing antioxidant defenses including through upregulation of the Nrf2 pathway, UA display neuroprotective effects in neuronal cells. The antiinflammatory action of UA such inhibition of key inflammatory cytokines via the NF- $\kappa$ B signalling pathways is also inhibited by UA. By acting on multiple targets and promotion of neuronal regenerations, UA has diverse function in the CNS. Symbols indicate the following: $(-)$ inhibition and $(+)$ promotion.

terpenoids even as small molecular size as monoterpenes could have antioxidant effects in vivo by inducing antioxidant defenses such as SOD, CAT, GPx, and GR as demonstrated for their therapeutic potential in $\mathrm{AD}$ through a variety of assay systems [111]. These terpenoids and even the polyphenolic compounds that display antioxidant effects do also possess anti-inflammatory properties. Hence, they are working to tackle complex diseases through what has been described as one drug $\rightarrow$ multitargets $\rightarrow$ one/many disease(s) therapeutic principle [112]. In this context, the therapeutic potential of UA as a prototype lead is shown in various CNS diseases primarily through antioxidant and anti-inflammatory mechanisms and also specific actions in various receptor/enzyme systems outlined in the preceding sections. Similarly, the antioxidant-anti-inflammatory axis has been shown to play a role in the antidiabetic effect of UA as demonstrated in the streptozotocin-induced rats $[113,114]$ in the $\mathrm{db} / \mathrm{db}$ diabetic mouse model [115], other models of diabetes nephropathies [116, 117], diabeticinduced monocyte dysfunction and atherosclerosis in mice [118], aortic injury in STZ-induced diabetic rats [119], or clinical trial in human [120]. The anti-inflammatory effect of UA in HFD-induced obese rats [121, 122], inhibition of lipoxygenase-1- (LOX-1-) mediated ROS generation and $\mathrm{NF}-\kappa \mathrm{B}$ activation as well as atherosclerosis development in mice [123], inhibition of matric metalloproteases in the aortic smooth muscle cells [124], cytokine-induced glioma cell invasion in the transwell cell migration assay [125], or cytokine expression in a macrophage and inhibition of atherosclerosis in mice [126] have also been shown.
The antioxidant and anti-inflammatory effects of UA were demonstrated in hepatoprotection through multiple pathways including antihyperlipidemic effect [127], the carbon tetrachloride- $\left(\mathrm{CCl}_{4^{-}}\right)$induced liver damage in mice [128-130], high choline diet-induced liver toxicity and endothelial dysfunction [131], ethanol-mediated experimental liver damage in rats [132], liver transplantation model in pigs [133], and LPS-induced hepatocyte damage [134]. The renoand cardioprotection of UA were similarly evident as demonstrated in the hypoxia-reoxygenation-induced myocardial injury cellular model in H9c2 cells [135], ischemia/reperfusion-induced acute kidney injury in rats [136], and chronic ethanol-induced oxidative stress in the rat heart [137].

UA ameliorates autoimmune arthritis [138], acute inflammation and adjuvant-induced chronic arthritis induced by zymosan in mice [139], or chronic constriction injury-induced neuropathic pain in rats [140]. Other antiinflammatory and antioxidant actions of UA were in the mouse model of allergic asthma [141], cigarette smokeinduced emphysema in rats as chronic obstructive pulmonary disease (COPD) [142], and the LPS-induced lung injury in mice [143]. The 2,4,6-trinitrobenzenesulfonic acid(TNBS-) induced colitis (colon shortening and myeloperoxidase (MPO) activity) model in the mouse model [144]; sepsis-induced acute kidney injury via inhibition of ROS and inflammatory cytokines, including TNF- $\alpha$, IL- $1 \beta$, and IL-6 in the kidney from septic mice [145]; sepsis induced in rats by cecal ligation and puncture [146]; LPS-induced acute inflammation model [147]; and various other multiple mechanisms including NF- $\kappa \mathrm{B}$ and STAT3 inhibition [148] have 
been demonstrated. All these data support the antiinflammatory mechanisms through inhibition of key inflammatory cytokines, COX and iNOS expressions, and antioxidant mechanisms including the activation of the Nrf2 pathway. Hence, the argument for the inflammatory and antioxidant mechanisms of neuroprotection by UA is also supported through the plethora of other systemic effects of UA in various experimental models. An overview of UA's action in CNS disorders is depicted in Figure 2.

\section{Conclusions}

Both as a component of common fruits, herbs, and medicinal plants as well as dietary supplements, UA is a natural product that has been safely used by humans in various forms. Among the plethora of pharmacological effects shown for UA is anti-inflammatory and antioxidant mechanisms in cellular and animal models. In parallel with its effects as antidiabetic, antiobesity, antihyperlipidemic, and hepato-, cardio-, and renoprotective agent and in chronic inflammation (arthritis, long injury, sepsis, and colitis) models, the CNS effect of UA has also been demonstrated. The brain injury, cerebral ischemia, cognition deficit, anxiety, and depression are used in this communication to appraise the therapeutic potential of UA. The antioxidant and anti-inflammatory mechanisms play a pivotal role for UA's effect while other mechanisms include specific effect on neurotransmitter uptake, receptor modulation, and enzyme inhibition, primarily $\mathrm{MAO}$ and $\mathrm{AChE}$. In view of such a diverse pharmacological effect/efficacy, a further lead optimisation study by using $\mathrm{UA}$ as a prototype drug candidate is well merited.

\section{Conflicts of Interest}

The author declares that there is no conflict of interests in this publication.

\section{References}

[1] J. Iqbal, B. A. Abbasi, R. Ahmad et al., "Ursolic acid a promising candidate in the therapeutics of breast cancer: current status and future implications," Biomedicine \& Pharmacotherapy, vol. 108, pp. 752-756, 2018.

[2] R. Yin, T. Li, J. X. Tian, P. Xi, and R. H. Liu, "Ursolic acid, a potential anticancer compound for breast cancer therapy," Critical Reviews in Food Science and Nutrition, vol. 58, no. 4, pp. 568-574, 2018.

[3] C. K. Katashima, V. R. Silva, T. L. Gomes, C. Pichard, and G. D. Pimentel, "Ursolic acid and mechanisms of actions on adipose and muscle tissue: a systematic review," Obesity Reviews, vol. 18, no. 6, pp. 700-711, 2017.

[4] A. M. Mancha-Ramirez and T. J. Slaga, "Ursolic acid and chronic disease: an overview of UA's effects on prevention and treatment of obesity and cancer," Advances in Experimental Medicine and Biology, vol. 928, pp. 75-96, 2016.

[5] D. Y. Seo, S. R. Lee, J. W. Heo et al., "Ursolic acid in health and disease," The Korean Journal of Physiology \& Pharmacology, vol. 22, no. 3, pp. 235-248, 2018.

[6] D. Kashyap, A. Sharma, H. S. Tuli, S. Punia, and A. K. Sharma, "Ursolic acid and oleanolic acid: pentacyclic terpenoids with promising anti-inflammatory activities," Recent Patents on Inflammation \& Allergy Drug Discovery, vol. 10, no. 1, pp. 21-33, 2016.

[7] J. Toglia and K. Golisz, "Traumatic brain injury (TBI) and the impact on daily life," in Changes in the Brain: Impact on Daily Life, pp. 117-143, Springer, 2017.

[8] C. K. Donat, G. Scott, S. M. Gentleman, and M. Sastre, "Microglial activation in traumatic brain injury," Frontiers in Aging Neuroscience, vol. 9, p. 208, 2017.

[9] S. W. Lee, S. Gajavelli, M. S. Spurlock et al., "Microglial inflammasome activation in penetrating ballistic-like brain injury," Journal of Neurotrauma, vol. 35, no. 14, pp. 1681-1693, 2018.

[10] S. A. Liddelow, K. A. Guttenplan, L. E. Clarke et al., "Neurotoxic reactive astrocytes are induced by activated microglia," Nature, vol. 541, no. 7638, pp. 481-487, 2017.

[11] A. Hasan, G. Deeb, R. Rahal et al., "Mesenchymal stem cells in the treatment of traumatic brain injury," Frontiers in Neurology, vol. 8, no. 28, 2017.

[12] S. L. James, A. Theadom, R. G. Ellenbogen et al., "Global, regional, and national burden of traumatic brain injury and spinal cord injury, 1990-2016: a systematic analysis for the Global Burden of Disease Study 2016," The Lancet Neurology, vol. 18, no. 1, pp. 56-87, 2019.

[13] M. Boldrini, C. A. Fulmore, A. N. Tartt et al., "Human hippocampal neurogenesis persists throughout aging," Cell Stem Cell, vol. 22, no. 4, pp. 589-599.e5, 2018.

[14] P. S. Eriksson, E. Perfilieva, T. Björk-Eriksson et al., "Neurogenesis in the adult human hippocampus," Nature Medicine, vol. 4, no. 11, pp. 1313-1317, 1998.

[15] K. L. Spalding, O. Bergmann, K. Alkass et al., "Dynamics of hippocampal neurogenesis in adult humans," Cell, vol. 153, no. 6, pp. 1219-1227, 2013.

[16] S. F. Sorrells, M. F. Paredes, A. Cebrian-Silla et al., "Human hippocampal neurogenesis drops sharply in children to undetectable levels in adults," Nature, vol. 555, no. 7696, pp. 377381, 2018.

[17] S. Habtemariam, "Molecular pharmacology of rosmarinic and salvianolic acids: potential seeds for Alzheimer's and vascular dementia drugs," International Journal of Molecular Sciences, vol. 19, no. 2, p. 458, 2018.

[18] H. Ding, H. Wang, L. Zhu, and W. Wei, "Ursolic acid ameliorates early brain injury after experimental traumatic brain injury in mice by activating the Nrf2 pathway," Neurochemical Research, vol. 42, no. 2, pp. 337-346, 2017.

[19] T. Zhang, J. Su, B. Guo, T. Zhu, K. Wang, and X. Li, "Ursolic acid alleviates early brain injury after experimental subarachnoid hemorrhage by suppressing TLR4-mediated inflammatory pathway," International Immunopharmacology, vol. 23, no. 2, pp. 585-591, 2014.

[20] T. Zhang, J. Su, K. Wang, T. Zhu, and X. Li, "Ursolic acid reduces oxidative stress to alleviate early brain injury following experimental subarachnoid hemorrhage," Neuroscience Letters, vol. 579, pp. 12-17, 2014.

[21] S. Sahu, R. Li, P. K. Kadeyala, S. Liu, and M. Schachner, "The human natural killer-1 (HNK-1) glycan mimetic ursolic acid promotes functional recovery after spinal cord injury in mouse," The Journal of Nutritional Biochemistry, vol. 55, pp. 219-228, 2018.

[22] L. Li, X. Zhang, L. Cui et al., "Ursolic acid promotes the neuroprotection by activating Nrf2 pathway after cerebral ischemia in mice," Brain Research, vol. 1497, pp. 32-39, 2013. 
[23] T. Nguyen, P. Nioi, and C. B. Pickett, "The Nrf2-antioxidant response element signaling pathway and its activation by oxidative stress," Journal of Biological Chemistry, vol. 284, no. 20, pp. 13291-13295, 2009.

[24] L. E. Tebay, H. Robertson, S. T. Durant et al., "Mechanisms of activation of the transcription factor Nrf2 by redox stressors, nutrient cues, and energy status and the pathways through which it attenuates degenerative disease," Free Radical Biology \& Medicine, vol. 88, Part B, pp. 108-146, 2015.

[25] K. Chen, K. Gunter, and M. D. Maines, "Neurons overexpressing heme oxygenase- 1 resist oxidative stress-mediated cell death," Journal of Neurochemistry, vol. 75, no. 1, pp. 304-313, 2000.

[26] D. R. Bruns, J. C. Drake, L. M. Biela, F. F. Peelor, B. F. Miller, and K. L. Hamilton, "Nrf2 signaling and the slowed aging phenotype: evidence from long-lived models," Oxidative Medicine and Cellular Longevity, vol. 2015, Article ID 732596, 15 pages, 2015.

[27] Y. Sun, T. Yang, R. K. Leak, J. Chen, and F. Zhang, "Preventive and protective roles of dietary Nrf2 activators against central nervous system diseases," CNS \& Neurological Disorders - Drug Targets, vol. 16, no. 3, pp. 326-338, 2017.

[28] A. Cuadrado, "NRF2 in neurodegenerative diseases," Current Opinion in Toxicology, vol. 1, pp. 46-53, 2016.

[29] Y. Wang, L. Li, S. Deng, F. Liu, and Z. He, "Ursolic acid ameliorates inflammation in cerebral ischemia and reperfusion injury possibly via high mobility group box $1 /$ toll-like receptor 4/NF- $\kappa$ B pathway," Frontiers in Neurology, vol. 9, p. 253, 2018.

[30] Q. W. Yang, J. Z. Wang, J. C. Li et al., "High-mobility group protein box-1 and its relevance to cerebral ischemia," Journal of Cerebral Blood Flow \& Metabolism, vol. 30, no. 2, pp. 243254, 2009.

[31] J. Qiu, M. Nishimura, Y. Wang et al., "Early release of HMGB-1 from neurons after the onset of brain ischemia," Journal of Cerebral Blood Flow \& Metabolism, vol. 28, no. 5, pp. 927-938, 2008.

[32] Y. Wang, Z. He, and S. Deng, "Ursolic acid reduces the metalloprotease/anti-metalloprotease imbalance in cerebral ischemia and reperfusion injury," Drug Design, Development and Therapy, vol. 10, pp. 1663-1674, 2016.

[33] Alzheimer's Disease International, "Dementia statistics," 2019, https://www.alz.co.uk/research/statistics.

[34] L. C. dos Santos Picanco, P. F. Ozela, M. de Fatima de Brito Brito et al., "Alzheimer's disease: a review from the pathophysiology to diagnosis, new perspectives for pharmacological treatment," Current Medicinal Chemistry, vol. 25, no. 26, pp. 3141-3159, 2018.

[35] M. Medina, "An overview on the clinical development of taubased therapeutics," International Journal of Molecular Sciences, vol. 19, no. 4, p. 1160, 2018.

[36] K. Mullane and M. Williams, “Alzheimer's disease (AD) therapeutics - 2: beyond amyloid - re-defining AD and its causality to discover effective therapeutics," Biochemical Pharmacology, vol. 158, pp. 376-401, 2018.

[37] P. Sharma, P. Srivastava, A. Seth, P. N. Tripathi, A. G. Banerjee, and S. K. Shrivastava, "Comprehensive review of mechanisms of pathogenesis involved in Alzheimer's disease and potential therapeutic strategies," Progress in Neurobiology, vol. 174, pp. 53-89, 2019.

[38] F. R. Tang, W. K. Loke, P. Wong, and B. C. Khoo, "Radioprotective effect of ursolic acid in radiation-induced impairment of neurogenesis, learning and memory in adolescent BALB/c mouse," Physiology \& Behavior, vol. 175, pp. 37-46, 2017.

[39] D. M. Wu, J. Lu, Y. Q. Zhang et al., "Ursolic acid improves domoic acid-induced cognitive deficits in mice," Toxicology and Applied Pharmacology, vol. 271, no. 2, pp. 127-136, 2013.

[40] J. S. Teitelbaum, R. J. Zatorre, S. Carpenter et al., "Neurologic sequelae of domoic acid intoxication due to the ingestion of contaminated mussels," New England Journal of Medicine, vol. 322, no. 25, pp. 1781-1787, 1990.

[41] J. Lu, D. M. Wu, Y. L. Zheng, B. Hu, W. Cheng, and Z. F. Zhang, "Purple sweet potato color attenuates domoic acidinduced cognitive deficits by promoting estrogen receptor$\alpha$-mediated mitochondrial biogenesis signaling in mice," Free Radical Biology \& Medicine, vol. 52, no. 3, pp. 646-659, 2012.

[42] Y. H. Shih, Y. C. Chein, J. Y. Wang, and Y. S. Fu, "Ursolic acid protects hippocampal neurons against kainate-induced excitotoxicity in rats," Neuroscience Letters, vol. 362, no. 2, pp. 136-140, 2004.

[43] J. Lu, Y. L. Zheng, D. M. Wu, L. Luo, D. X. Sun, and Q. Shan, "Ursolic acid ameliorates cognition deficits and attenuates oxidative damage in the brain of senescent mice induced by D-galactose," Biochemical Pharmacology, vol. 74, no. 7, pp. 1078-1090, 2007.

[44] S. A. Bahrami and N. Bakhtiari, "Ursolic acid regulates aging process through enhancing of metabolic sensor proteins level," Biomedicine \& Pharmacotherapy, vol. 82, pp. 8-14, 2016.

[45] K. Akasaka-Manya, H. Manya, and T. Endo, "Function and change with aging of $\alpha$-Klotho in the kidney," Vitamins \& Hormones, vol. 101, pp. 239-256, 2016.

[46] M. M. Cararo-Lopes, C. H. Y. Mazucanti, C. Scavone, E. M. Kawamoto, and D. C. Berwick, "The relevance of $\alpha$-Klotho to the central nervous system: some key questions," Ageing Research Reviews, vol. 36, pp. 137-148, 2017.

[47] H. Kurosu, M. Yamamoto, J. D. Clark et al., "Suppression of aging in mice by the hormone Klotho," Science, vol. 309, no. 5742, pp. 1829-1833, 2005.

[48] Y. Xu and Z. Sun, "Molecular basis of Klotho: from gene to function in aging," Endocrine Reviews, vol. 36, no. 2, pp. 174-193, 2015.

[49] S. Gharibi, N. Bakhtiari, E. M. Jalalvand, and F. Bakhtiari, "Ursolic acid mediates hepatic protection through enhancing of anti-aging biomarkers," Current Aging Science, vol. 11, no. 1, pp. 16-23, 2018.

[50] J. Lu, D. M. Wu, Y. L. Zheng et al., "Ursolic acid attenuates Dgalactose-induced inflammatory response in mouse prefrontal cortex through inhibiting AGEs/RAGE/NF- $\kappa$ B pathway activation," Cerebral Cortex, vol. 20, no. 11, pp. 2540-2548, 2010.

[51] Y. J. Wang, J. Lu, D. M. Wu et al., "Ursolic acid attenuates lipopolysaccharide-induced cognitive deficits in mouse brain through suppressing $\mathrm{p} 38 / \mathrm{NF}-\kappa \mathrm{B}$ mediated inflammatory pathways," Neurobiology of Learning and Memory, vol. 96, no. 2, pp. 156-165, 2011.

[52] J. Lu, D. M. Wu, Y. L. Zheng et al., "Ursolic acid improves high fat diet-induced cognitive impairments by blocking endoplasmic reticulum stress and $\mathrm{I} \kappa \mathrm{B}$ kinase $\beta /$ nuclear factor- $\kappa \mathrm{B}$-mediated inflammatory pathways in mice," Brain, Behavior, and Immunity, vol. 25, no. 8, pp. 1658-1667, 2011.

[53] A. Mourya, A. Akhtar, S. Ahuja, S. P. Sah, and A. Kumar, "Synergistic action of ursolic acid and metformin in 
experimental model of insulin resistance and related behavioral alterations," European Journal of Pharmacology, vol. 835, pp. 31-40, 2018.

[54] W. Liang, X. Zhao, J. Feng, F. Song, and Y. Pan, "Ursolic acid attenuates beta-amyloid-induced memory impairment in mice," Arquivos de Neuro-Psiquiatria, vol. 74, no. 6, pp. $482-488,2016$.

[55] J. H. Yoon, K. Youn, C. T. Ho, M. V. Karwe, W. S. Jeong, and M. Jun, " $p$-Coumaric acid and ursolic acid from Corni fructus attenuated $\beta$-amyloid ${ }_{25-35}$-induced toxicity through regulation of the NF- $\kappa \mathrm{B}$ signaling pathway in PC12 cells," Journal of Agricultural and Food Chemistry, vol. 62, no. 21, pp. 4911-4916, 2014.

[56] H. J. Heo, H. Y. Cho, B. Hong et al., "Ursolic acid of Origanum majorana $\mathrm{L}$. reduces A $\beta$-induced oxidative injury," Molecules and Cells, vol. 13, no. 1, pp. 5-11, 2002.

[57] S. Y. Hong, W. S. Jeong, and M. Jun, "Protective effects of the key compounds isolated from Corni fructus against $\beta$-amyloid-induced neurotoxicity in PC12 cells," Molecules, vol. 17, no. 9, pp. 10831-10845, 2012.

[58] K. Wilkinson, J. D. Boyd, M. Glicksman, K. J. Moore, and J. El Khoury, "A high content drug screen identifies ursolic acid as an inhibitor of amyloid $\beta$ protein interactions with its receptor CD36," Journal of Biological Chemistry, vol. 286, no. 40, pp. 34914-34922, 2011.

[59] I. S. Coraci, J. Husemann, J. W. Berman et al., "CD36, a class B scavenger receptor, is expressed on microglia in Alzheimer's disease brains and can mediate production of reactive oxygen species in response to $\beta$-amyloid fibrils," The American Journal of Pathology, vol. 160, no. 1, pp. 101-112, 2002.

[60] J. B. El Khoury, K. J. Moore, T. K. Means et al., "CD36 mediates the innate host response to $\beta$-amyloid," The Journal of Experimental Medicine, vol. 197, no. 12, pp. 16571666, 2003.

[61] Y. K. Chung, H. J. Heo, E. K. Kim et al., "Inhibitory effect of ursolic acid purified from Origanum majorana L. on the acetylcholinesterase," Molecules and Cells, vol. 11, no. 2, pp. 137143, 2001.

[62] A. Loesche, A. Köwitsch, S. D. Lucas et al., "Ursolic and oleanolic acid derivatives with cholinesterase inhibiting potential," Bioorganic Chemistry, vol. 85, pp. 23-32, 2019.

[63] J. C. Felger, "Imaging the role of inflammation in mood and anxiety-related disorders," Current Neuropharmacology, vol. 16, no. 5, pp. 533-558, 2018.

[64] S. A. Syed, E. Beurel, D. A. Loewenstein et al., "Defective inflammatory pathways in never-treated depressed patients are associated with poor treatment response," Neuron, vol. 99, no. 5, pp. 914-924.e3, 2018.

[65] L. Leng, K. Zhuang, Z. Liu et al., "Menin deficiency leads to depressive-like behaviors in mice by modulating astrocytemediated neuroinflammation," Neuron, vol. 100, no. 3, pp. 551-563.e7, 2018.

[66] L. Ma, K. A. Demin, T. O. Kolesnikova et al., "Animal inflammation-based models of depression and their application to drug discovery," Expert Opinion on Drug Discovery, vol. 12, no. 10, pp. 995-1009, 2017.

[67] B. Grygiel-Górniak, N. Limphaibool, and M. Puszczewicz, "Cytokine secretion and the risk of depression development in patients with connective tissue diseases," Psychiatry and Clinical Neurosciences, 2019, In press.
[68] C. Fourrier, G. Singhal, and B. T. Baune, "Neuroinflammation and cognition across psychiatric conditions," CNS Spectrums, vol. 24, no. 1, pp. 4-15, 2019.

[69] K. L. Chan, F. Cathomas, and S. J. Russo, "Central and peripheral inflammation link metabolic syndrome and major depressive disorder," Physiology, vol. 34, no. 2, pp. 123-133, 2019.

[70] K. Tolkien, S. Bradburn, and C. Murgatroyd, "An antiinflammatory diet as a potential intervention for depressive disorders: a systematic review and meta-analysis," Clinical Nutrition, 2018, In press.

[71] A. D. G. Fedoce, F. Ferreira, R. G. Bota, V. Bonet-Costa, P. Y. Sun, and K. J. A. Davies, "The role of oxidative stress in anxiety disorder: cause or consequence?," Free Radical Research, vol. 52, no. 7, pp. 737-750, 2018.

[72] L. Hritcu, R. Ionita, P. A. Postu et al., "Antidepressant flavonoids and their relationship with oxidative stress," Oxidative Medicine and Cellular Longevity, vol. 2017, Article ID 5762172, 18 pages, 2017.

[73] D. Nieoczym, K. Socała, and P. Wlaź, "Assessment of the anticonvulsant potency of ursolic acid in seizure threshold tests in mice," Neurochemical Research, vol. 43, no. 5, pp. 995-1002, 2018.

[74] M. F. Taviano, N. Miceli, M. T. Monforte, O. Tzakou, and E. M. Galati, "Ursolic acid plays a role in Nepeta sibthorpii Bentham CNS depressing effects," Phytotherapy Research, vol. 21, no. 4, pp. 382-385, 2007.

[75] P. S. Brocardo, J. Budni, K. R. Lobato, A. R. S. Santos, and A. L. S. Rodrigues, "Evidence for the involvement of the opioid system in the antidepressant-like effect of folic acid in the mouse forced swimming test," Behavioural Brain Research, vol. 200, no. 1, pp. 122-127, 2009.

[76] S. Schreiber, A. Bleich, and C. G. Pick, "Venlafaxine and mirtazapine: different mechanisms of antidepressant action, common opioid-mediated antinociceptive effects-a possible opioid involvement in severe depression?," Journal of Molecular Neuroscience, vol. 18, no. 1-2, pp. 143-150, 2002.

[77] D. G. Machado, V. B. Neis, G. O. Balen et al., "Antidepressant-like effect of ursolic acid isolated from Rosmarinus officinalis L. in mice: evidence for the involvement of the dopaminergic system," Pharmacology Biochemistry and Behavior, vol. 103, no. 2, pp. 204-211, 2012.

[78] A. R. S. Colla, Á. Oliveira, F. L. Pazini et al., "Serotonergic and noradrenergic systems are implicated in the antidepressantlike effect of ursolic acid in mice," Pharmacology Biochemistry and Behavior, vol. 124, pp. 108-116, 2014.

[79] A. R. S. Colla, J. M. Rosa, M. P. Cunha, and A. L. S. Rodrigues, "Anxiolytic-like effects of ursolic acid in mice," European Journal of Pharmacology, vol. 758, pp. 171-176, 2015.

[80] J. Verano, M. E. González-Trujano, M. Déciga-Campos, R. Ventura-Martínez, and F. Pellicer, "Ursolic acid from Agastache mexicana aerial parts produces antinociceptive activity involving TRPV1 receptors, cGMP and a serotonergic synergism," Pharmacology Biochemistry and Behavior, vol. 110, pp. 255-264, 2013.

[81] A. B. Ramos-Hryb, M. P. Cunha, F. L. Pazini et al., "Ursolic acid affords antidepressant-like effects in mice through the activation of PKA, PKC, CAMK-II and MEK1/2," Pharmacological Reports, vol. 69, no. 6, pp. 1240-1246, 2017.

[82] J. H. Liu, Z. F. Wu, J. Sun, L. Jiang, S. Jiang, and W. B. Fu, "Role of AC-cAMP-PKA cascade in antidepressant action 
of electroacupuncture treatment in rats," Evidence-Based Complementary and Alternative Medicine, vol. 2012, Article ID 932414, 7 pages, 2012.

[83] G. Z. Réus, R. B. Stringari, K. F. Ribeiro et al., "Ketamine plus imipramine treatment induces antidepressant-like behavior and increases CREB and BDNF protein levels and PKA and PKC phosphorylation in rat brain," Behavioural Brain Research, vol. 221, no. 1, pp. 166-171, 2011.

[84] E. Tiraboschi, R. Giambelli, G. D’Urso et al., "Antidepressants activate CaMKII in neuron cell body by Thr286 phosphorylation," NeuroReport, vol. 15, no. 15, pp. 2393-2396, 2004.

[85] C. H. Duman, L. Schlesinger, M. Kodama, D. S. Russell, and R. S. Duman, "A role for MAP kinase signaling in behavioral models of depression and antidepressant treatment," Biological Psychiatry, vol. 61, no. 5, pp. 661-670, 2007.

[86] I. Khan, N. Karim, W. Ahmad, A. Abdelhalim, and M. Chebib, "GABA-A receptor modulation and anticonvulsant, anxiolytic, and antidepressant activities of constituents from Artemisia indica Linn," Evidence-Based Complementary and Alternative Medicine, vol. 2016, Article ID 1215393, 12 pages, 2016.

[87] S. J. Jeon, H. J. Park, Q. Gao et al., "Ursolic acid enhances pentobarbital-induced sleeping behaviors via GABAergic neurotransmission in mice," European Journal of Pharmacology, vol. 762, pp. 443-448, 2015.

[88] R. Awad, A. Muhammad, T. Durst, V. L. Trudeau, and J. T. Arnason, "Bioassay-guided fractionation of lemon balm (Melissa officinalis L.) using an in vitro measure of GABA transaminase activity," Phytotherapy Research, vol. 23, no. 8, pp. 1075-1081, 2009.

[89] R. K. Singla, L. Scotti, and A. K. Dubey, "In silico studies revealed multiple neurological targets for the antidepressant molecule ursolic acid," Current Neuropharmacology, vol. 15, no. 8, pp. 1100-1106, 2017.

[90] J. H. Kim, G. H. Kim, and K. H. Hwang, "Monoamine oxidase and dopamine $\beta$-hydroxylase inhibitors from the fruits of Gardenia jasminoides," Biomolecules \& Therapeutics, vol. 20, no. 2, pp. 214-219, 2012.

[91] S. H. Appel, D. R. Beers, and J. S. Henkel, "T cell-microglial dialogue in Parkinson's disease and amyotrophic lateral sclerosis: are we listening?," Trends in Immunology, vol. 31, no. 1, pp. 7-17, 2010.

[92] Y. Chao, S. C. Wong, and E. K. Tan, "Evidence of inflammatory system involvement in Parkinson's disease," BioMed Research International, vol. 2014, Article ID 308654, 9 pages, 2014.

[93] R. L. Mosley, E. J. Benner, I. Kadiu et al., "Neuroinflammation, oxidative stress and the pathogenesis of Parkinson's disease," Clinical Neuroscience Research, vol. 6, no. 5, pp. 261281, 2006.

[94] M. Varçin, E. Bentea, Y. Michotte, and S. Sarre, "Oxidative stress in genetic mouse models of Parkinson's disease," Oxidative Medicine and Cellular Longevity, vol. 2012, Article ID 624925, 25 pages, 2012.

[95] C. Knott, G. Stern, and G. P. Wilkin, "Inflammatory regulators in Parkinson's disease: iNOS, lipocortin-1, and cyclooxygenases-1 and -2," Molecular and Cellular Neuroscience, vol. 16, no. 6, pp. 724-739, 2000.

[96] M. Li, F. R. Dai, X. P. Du, Q. D. Yang, and Y. Chen, "Neuroprotection by silencing iNOS expression in a 6-OHDA model of Parkinson's disease," Journal of Molecular Neuroscience, vol. 48, no. 1, pp. 225-233, 2012.

[97] Q. Wang, H. Zhang, M. Liu et al., "P38 MAPK signaling pathway regulates nuclear factor- $\kappa \mathrm{B}$ and inducible nitric oxide synthase expressions in the substantia nigra in a mouse model of Parkinson's disease," Journal of Southern Medical University, vol. 34, no. 8, pp. 1176-1180, 2014.

[98] H. Wilms, P. Rosenstiel, J. Sievers, G. Deuschl, L. Zecca, and R. Lucius, "Activation of microglia by human neuromelanin is NF- $\kappa \mathrm{B}$ dependent and involves p38 mitogen-activated protein kinase: implications for Parkinson's disease," The FASEB Journal, vol. 17, no. 3, pp. 500-502, 2003.

[99] S. K. Jha, N. K. Jha, R. Kar, R. K. Ambasta, and P. Kumar, "p38 MAPK and PI3K/AKT signalling cascades in Parkinson's disease," International Journal of Molecular and Cellular Medicine, vol. 4, no. 2, pp. 67-86, 2015.

[100] S. Karunakaran and V. Ravindranath, "Activation of p38 MAPK in the substantia nigra leads to nuclear translocation of NF- $\kappa$ B in MPTP-treated mice: implication in Parkinson's disease," Journal of Neurochemistry, vol. 109, no. 6, pp. 1791-1799, 2009.

[101] P. Chan, L. E. DeLanney, I. Irwin, J. W. Langston, and D. Monte, "Rapid ATP loss caused by 1-methyl-4-phenyl1,2,3,6-tetrahydropyridine in mouse brain," Journal of Neurochemistry, vol. 57, no. 1, pp. 348-351, 1991.

[102] G. S. Gaki and A. G. Papavassiliou, "Oxidative stress-induced signaling pathways implicated in the pathogenesis of Parkinson's disease," NeuroMolecular Medicine, vol. 16, no. 2, pp. 217-230, 2014.

[103] C. Zhou, Y. Huang, and S. Przedborski, "Oxidative stress in Parkinson's disease: a mechanism of pathogenic and therapeutic significance," Annals of the New York Academy of Sciences, vol. 1147, no. 1, pp. 93-104, 2008.

[104] S. N. Rai, H. Dilnashin, H. Birla et al., "The role of PI3K/Akt and ERK in neurodegenerative disorders," Neurotoxicity Research, vol. 35, no. 3, pp. 775-795, 2019.

[105] S. N. Rai, S. K. Yadav, D. Singh, and S. P. Singh, "Ursolic acid attenuates oxidative stress in nigrostriatal tissue and improves neurobehavioral activity in MPTP-induced Parkinsonian mouse model," Journal of Chemical Neuroanatomy, vol. 71, pp. 41-49, 2016.

[106] S. Habtemariam, "Protective effects of caffeic acid and the Alzheimer's brain: an update," Mini-Reviews in Medicinal Chemistry, vol. 17, no. 8, pp. 667-674, 2017.

[107] S. Habtemariam, "The brain-derived neurotrophic factor in neuronal plasticity and neuroregeneration: new pharmacological concepts for old and new drugs," Neural Regeneration Research, vol. 13, no. 6, pp. 983-984, 2018.

[108] S. Habtemariam, "Rutin as a natural therapy for Alzheimer's disease: insights into its mechanisms of action," Current Medicinal Chemistry, vol. 23, no. 9, pp. 860-873, 2016.

[109] T. O. Elufioye, T. I. Berida, and S. Habtemariam, "Plantsderived neuroprotective agents: cutting the cycle of cell death through multiple mechanisms," Evidence-Based Complementary and Alternative Medicine, vol. 2017, Article ID 3574012, 27 pages, 2017.

[110] S. Habtemariam, "The therapeutic potential of rosemary (Rosmarinus officinalis) diterpenes for Alzheimer's disease," Evidence-Based Complementary and Alternative Medicine, vol. 2016, Article ID 2680409, 14 pages, 2016. 
[111] S. Habtemariam, "Iridoids and other monoterpenes in the Alzheimer's brain: recent development and future prospects," Molecules, vol. 23, no. 1, p. 117, 2018.

[112] S. Habtemariam, "Going back to the good old days: the merit of crude plant drug mixtures in the $21^{\text {st }}$ century," International Journal of Complementary \& Alternative Medicine, vol. 6, no. 2, article 00182, 2017.

[113] H. L. Xu, X. T. Wang, Y. Cheng et al., "Ursolic acid improves diabetic nephropathy via suppression of oxidative stress and inflammation in streptozotocin-induced rats," Biomedicine \& Pharmacotherapy, vol. 105, pp. 915-921, 2018.

[114] X. T. Wang, Y. Gong, B. Zhou et al., "Ursolic acid ameliorates oxidative stress, inflammation and fibrosis in diabetic cardiomyopathy rats," Biomedicine \& Pharmacotherapy, vol. 97, pp. 1461-1467, 2018.

[115] J. S. Li, W. J. Wang, Y. Sun, Y. H. Zhang, and L. Zheng, "Ursolic acid inhibits the development of nonalcoholic fatty liver disease by attenuating endoplasmic reticulum stress," Food \& Function, vol. 6, no. 5, pp. 1643-1651, 2015.

[116] J. Li, N. Li, S. Yan et al., "Ursolic acid alleviates inflammation and against diabetes-induced nephropathy through TLR4mediated inflammatory pathway," Molecular Medicine Reports, vol. 18, no. 5, pp. 4675-4681, 2018.

[117] E. M. Wang, Q. L. Fan, Y. Yue, and L. Xu, "Ursolic acid attenuates high glucose-mediated mesangial cell injury by inhibiting the phosphatidylinositol 3-kinase/Akt/mammalian target of rapamycin (PI3K/Akt/mTOR) signaling pathway," Medical Science Monitor, vol. 24, pp. 846-854, 2018.

[118] S. L. Ullevig, Q. Zhao, D. Zamora, and R. Asmis, "Ursolic acid protects diabetic mice against monocyte dysfunction and accelerated atherosclerosis," Atherosclerosis, vol. 219, no. 2, pp. 409-416, 2011.

[119] M. Xiang, J. Wang, Y. Zhang, J. Ling, and X. Xu, “Attenuation of aortic injury by ursolic acid through RAGE-Nox-NF- $\kappa \mathrm{B}$ pathway in streptozocin-induced diabetic rats," Archives of Pharmacal Research, vol. 35, no. 5, pp. 877-886, 2012.

[120] A. M. Ramírez-Rodríguez, M. González-Ortiz, E. MartínezAbundis, and N. Acuña Ortega, "Effect of ursolic acid on metabolic syndrome, insulin sensitivity, and inflammation," Journal of Medicinal Food, vol. 20, no. 9, pp. 882-886, 2017.

[121] Y. Zhang, C. Song, H. Li, J. Hou, and D. Li, "Ursolic acid prevents augmented peripheral inflammation and inflammatory hyperalgesia in high-fat diet-induced obese rats by restoring downregulated spinal PPAR $\alpha$," Molecular Medicine Reports, vol. 13, no. 6, pp. 5309-5316, 2016.

[122] S. Li, F. Meng, X. Liao et al., "Therapeutic role of ursolic acid on ameliorating hepatic steatosis and improving metabolic disorders in high-fat diet-induced non-alcoholic fatty liver disease rats," PLoS One, vol. 9, no. 1, article e86724, 2014.

[123] Q. Li, W. Zhao, X. Zeng, and Z. Hao, "Ursolic acid attenuates atherosclerosis in $\mathrm{ApoE}^{-1-}$ mice: role of LOX-1 mediated by ROS/NF- $\kappa$ B pathway," Molecules, vol. 23, no. 5, p. 1101, 2018.

[124] M. Zhai, J. Guo, H. Ma et al., "Ursolic acid prevents angiotensin II-induced abdominal aortic aneurysm in apolipoprotein E-knockout mice," Atherosclerosis, vol. 271, pp. 128-135, 2018.

[125] H. C. Huang, C. Y. Huang, S. Y. Lin-Shiau, and J. K. Lin, "Ursolic acid inhibits IL- $1 \beta$ or TNF- $\alpha$-induced C6 glioma invasion through suppressing the association ZIP/p62 with PKC- $\zeta$ and downregulating the MMP-9 expression," Molecular Carcinogenesis, vol. 48, no. 6, pp. 517-531, 2009.
[126] S. Leng, S. Iwanowycz, F. Saaoud et al., "Ursolic acid enhances macrophage autophagy and attenuates atherogenesis," Journal of Lipid Research, vol. 57, no. 6, pp. 1006-1016, 2016.

[127] Y. L. Wang, Z. J. Wang, H. L. Shen, M. Yin, and K. X. Tang, "Effects of artesunate and ursolic acid on hyperlipidemia and its complications in rabbit," European Journal of Pharmaceutical Sciences, vol. 50, no. 3-4, pp. 366-371, 2013.

[128] J. Q. Ma, J. Ding, L. Zhang, and C. M. Liu, "Protective effects of ursolic acid in an experimental model of liver fibrosis through Nrf2/ARE pathway," Clinics and Research in Hepatology and Gastroenterology, vol. 39, no. 2, pp. 188-197, 2015.

[129] J. Q. Ma, J. Ding, L. Zhang, and C. M. Liu, "Ursolic acid protects mouse liver against $\mathrm{CCl}_{4}$-induced oxidative stress and inflammation by the MAPK/NF- $\kappa$ B pathway," Environmental Toxicology and Pharmacology, vol. 37, no. 3, pp. 975983, 2014.

[130] J. Q. Ma, J. Ding, Z. H. Xiao, and C. M. Liu, "Ursolic acid ameliorates carbon tetrachloride-induced oxidative DNA damage and inflammation in mouse kidney by inhibiting the STAT3 and NF- $\kappa \mathrm{B}$ activities," International Immunopharmacology, vol. 21, no. 2, pp. 389-395, 2014.

[131] D. Li, D. Ren, Y. Luo, and X. Yang, "Protective effects of ursolic acid against hepatotoxicity and endothelial dysfunction in mice with chronic high choline diet consumption," ChemicoBiological Interactions, vol. 258, pp. 102-107, 2016.

[132] R. Saravanan and V. Pugalendi, "Impact of ursolic acid on chronic ethanol-induced oxidative stress in the rat heart," Pharmacological Reports, vol. 58, no. 1, pp. 41-47, 2006.

[133] W. Zhou, L. Lin, Y. Cheng, and Y. Liu, "Ursolic acid improves liver transplantation and inhibits apoptosis in miniature pigs using donation after cardiac death," Cellular Physiology and Biochemistry, vol. 43, no. 1, pp. 331-338, 2017.

[134] Y. Yang, Z. Zhao, Y. Liu, X. Kang, H. Zhang, and M. Meng, "Suppression of oxidative stress and improvement of liver functions in mice by ursolic acid via LKB1-AMP-activated protein kinase signaling," Journal of Gastroenterology and Hepatology, vol. 30, no. 3, pp. 609-618, 2015.

[135] M. Chen, X. Wang, B. Hu et al., "Ursolic acid stimulates $\mathrm{UCP} 2$ expression and protects $\mathrm{H} 9 \mathrm{c} 2$ cells from hypoxiareoxygenation injury via p38 signaling," Journal of Biosciences, vol. 43, no. 5, pp. 857-865, 2018.

[136] J. Peng, X. Ren, T. Lan, Y. Chen, Z. Shao, and C. Yang, "Renoprotective effects of ursolic acid on ischemia/reperfusioninduced acute kidney injury through oxidative stress, inflammation and the inhibition of STAT3 and NF- $\kappa$ B activities," Molecular Medicine Reports, vol. 14, no. 4, pp. 3397-3402, 2016.

[137] R. Saravanan, P. Viswanathan, and K. V. Pugalendi, "Protective effect of ursolic acid on ethanol-mediated experimental liver damage in rats," Life Sciences, vol. 78, no. 7, pp. 713$718,2006$.

[138] S. Y. Baek, J. Lee, D. G. Lee et al., "Ursolic acid ameliorates autoimmune arthritis via suppression of Th17 and B cell differentiation," Acta Pharmacologica Sinica, vol. 35, no. 9, pp. 1177-1187, 2014.

[139] S. Y. Kang, S. Y. Yoon, D. H. Roh et al., "The anti-arthritic effect of ursolic acid on zymosan-induced acute inflammation and adjuvant-induced chronic arthritis models," Journal of Pharmacy and Pharmacology, vol. 60, no. 10, pp. 1347$1354,2008$. 
[140] R. A. Bhat, M. C. Lingaraju, N. N. Pathak et al., "Effect of ursolic acid in attenuating chronic constriction injuryinduced neuropathic pain in rats," Fundamental \& Clinical Pharmacology, vol. 30, no. 6, pp. 517-528, 2016.

[141] S. H. Kim, J. H. Hong, and Y. C. Lee, "Ursolic acid, a potential PPAR $\gamma$ agonist, suppresses ovalbumin-induced airway inflammation and Penh by down-regulating IL-5, IL-13, and IL-17 in a mouse model of allergic asthma," European Journal of Pharmacology, vol. 701, no. 1-3, pp. 131-143, 2013.

[142] L. Lin, Y. Yin, G. Hou, D. Han, J. Kang, and Q. Wang, "Ursolic acid attenuates cigarette smoke-induced emphysema in rats by regulating PERK and Nrf2 pathways," Pulmonary Pharmacology \& Therapeutics, vol. 44, pp. 111-121, 2017.

[143] X. Chen, Y. Wan, T. Zhou, J. Li, and Y. Wei, "Ursolic acid attenuates lipopolysaccharide-induced acute lung injury in a mouse model," Immunotherapy, vol. 5, no. 1, pp. 39-47, 2013.

[144] S. E. Jang, J. J. Jeong, S. R. Hyam, M. J. Han, and D. H. Kim, "Ursolic acid isolated from the seed of Cornus officinalis ameliorates colitis in mice by inhibiting the binding of lipopolysaccharide to Toll-like receptor 4 on macrophages," Journal of Agricultural and Food Chemistry, vol. 62, no. 40, pp. 9711-9721, 2014.

[145] Z. Zhang, H. Zhang, R. Chen, and Z. Wang, "Oral supplementation with ursolic acid ameliorates sepsis-induced acute kidney injury in a mouse model by inhibiting oxidative stress and inflammatory responses," Molecular Medicine Reports, vol. 17, no. 5, pp. 7142-7148, 2018.

[146] Z. Hu, Z. Gu, M. Sun et al., "Ursolic acid improves survival and attenuates lung injury in septic rats induced by cecal ligation and puncture," Journal of Surgical Research, vol. 194, no. 2, pp. 528-536, 2015.

[147] C. Zhang, C. Wang, W. Li et al., "Pharmacokinetics and pharmacodynamics of the triterpenoid ursolic acid in regulating the antioxidant, anti-inflammatory, and epigenetic gene responses in rat leukocytes," Molecular Pharmaceutics, vol. 14, no. 11, pp. 3709-3717, 2017.

[148] X. Ma, Y. Zhang, Z. Wang et al., "Ursolic acid, a natural nutraceutical agent, targets caspase 3 and alleviates inflammation-associated downstream signal transduction," Molecular Nutrition \& Food Research, vol. 61, no. 12, 2017. 


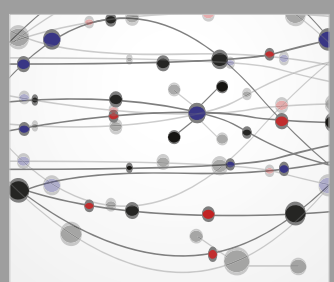

The Scientific World Journal
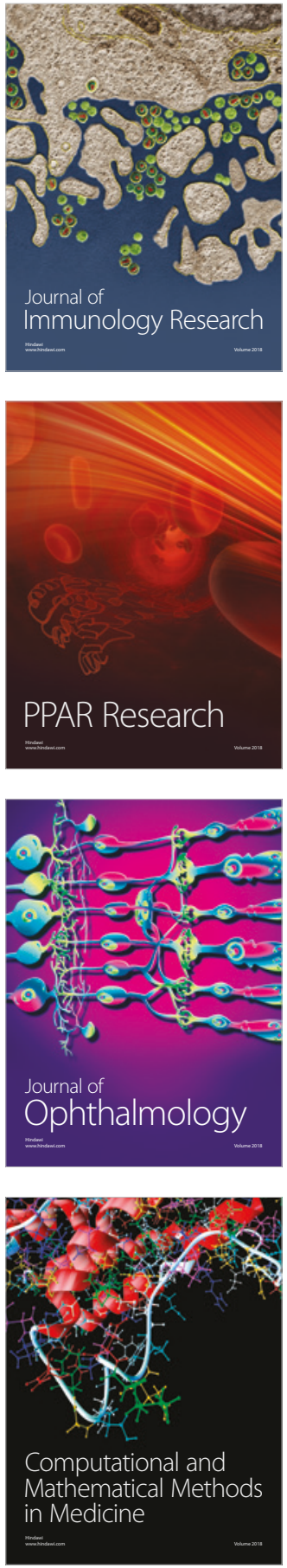

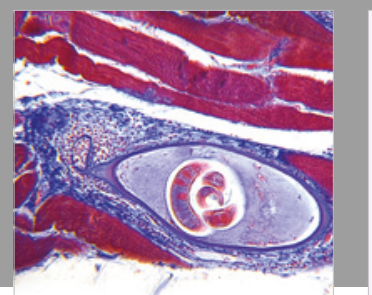

Gastroenterology Research and Practice

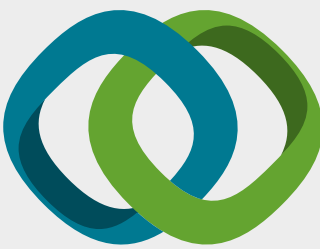

\section{Hindawi}

Submit your manuscripts at

www.hindawi.com
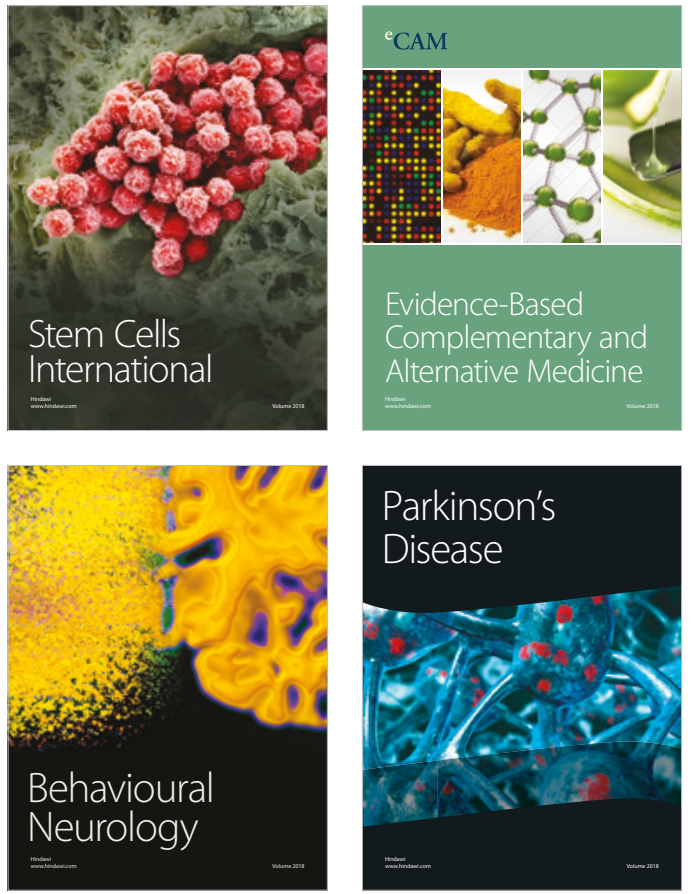

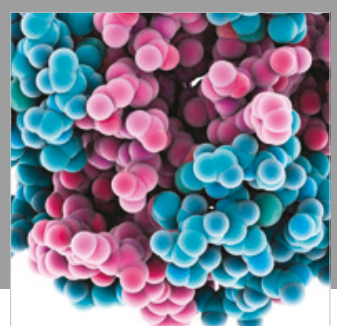

ournal of

Diabetes Research

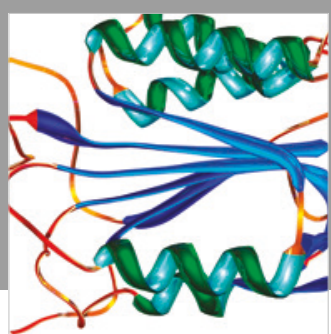

Disease Markers
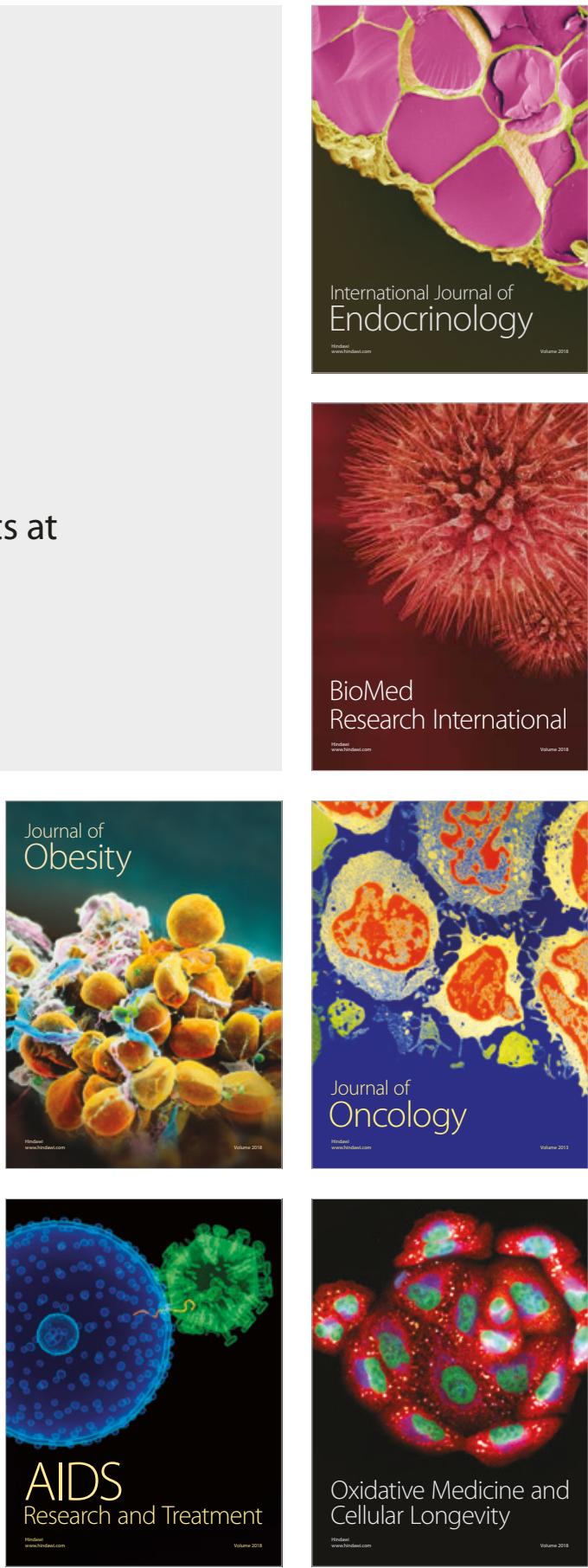